\title{
Effects of Hypervelocity Impacts on Silicone Elastomer Seals and Mating Aluminum Surfaces
}

\author{
Henry C. de Groh III $^{1}$ and Bruce M. Steinetz ${ }^{2}$ \\ NASA Glenn Research Center, Cleveland, Ohio 44135
}

\begin{abstract}
While in space silicone based elastomer seals planned for use on NASA's Crew Exploration Vehicle (CEV) are exposed to threats from micrometeoroids and orbital debris (MMOD). An understanding of these threats is required to assess risks to the crew, the CEV orbiter, and missions. An Earth based campaign of hypervelocity impacts on small scale seal rings has been done to help estimate MMOD threats to the primary docking seal being developed for the Low Impact Docking System (LIDS). LIDS is being developed to enable the CEV to dock to the ISS (International Space Station) or to Altair (NASA's next lunar lander). The silicone seal on LIDS seals against aluminum alloy flanges on ISS or Altair. Since the integrity of a seal depends on both sealing surfaces, aluminum targets were also impacted. The variables considered in this study included projectile mass, density, speed, incidence angle, seal materials, and target surface treatments and coatings. Most of the impacts used a velocity near $8 \mathrm{~km} / \mathrm{s}$ and spherical aluminum projectiles (density $=2.7 \mathrm{~g} / \mathrm{cm}^{3}$ ), however, a few tests were done near $5.6 \mathrm{~km} / \mathrm{s}$. Tests were also performed using projectile densities of 7.7, 2.79, 2.5 or $1.14 \mathrm{~g} / \mathrm{cm}^{3}$. Projectile incidence angles examined included $0^{\circ}$, $45^{\circ}$, and $60^{\circ}$ from normal to the plane of the target. Elastomer compounds impacted include Parker's S0383-70 and Esterline's ELA-SA-401 in the as received condition, or after an atomic oxygen treatment. Bare, anodized and nickel coated aluminum targets were tested simulating the candidate mating seal surface materials. After impact, seals and aluminum plates were leak tested: damaged seals were tested against an undamaged aluminum plate; and undamaged seals were placed at various locations over craters in aluminum plates. It has been shown that silicone elastomer seals can withstand an impressive level of damage before leaking beyond allowable limits. In general on the tests performed to date, the diameter of the crater in either the elastomer, or the aluminum, must be at least as big as $80 \%$ to $90 \%$ of width of the bulb of the seal before significant leakage occurs.
\end{abstract}

\section{Nomenclature}

$C=$ speed of sound in the target, $\mathrm{m} / \mathrm{s}$

$c-c=$ distance between the center of the crater and the center-line of the seal, $\mathrm{mm}$

$d \quad=$ projectile diameter

$D_{\text {seal }}=$ average diameter of the crater in the elastomer, $=\left(d_{v}+d_{s}+d_{c}\right) / 3, \mathrm{~mm}$

$D_{f} \quad=$ average diameter of the crater in the flange material, in this case, aluminum alloy, $=\left(d_{f i}+d_{f o}\right) / 2, \mathrm{~mm}$

$d_{f i} \quad=$ average inner diameter of the crater, in plane with the surface of the metal target, $\mathrm{mm}$

$d_{f o} \quad=$ average outer diameter of the crater, the outer diameter of the metal crater's crown, $\mathrm{mm}$

$d_{v} \quad=$ average maximum diameter vaporized in the crater in the elastomer, $\mathrm{mm}$

$d_{s} \quad=$ average diameter of secondary crater damage in the elastomer, $\mathrm{mm}$

$d_{c} \quad=$ average diameter of radial cracks in the elastomer, $\mathrm{mm}$

$D_{\text {crit }} \quad=$ the minimum crater diameter that causes seal or flange failure, the "critical" crater diameter, mm

$h=$ crown height of the crater, $\mathrm{mm}$

$H \quad=$ Brinell Hardness of the target

$K E \quad=$ kinetic energy, joules, $\mathrm{J}$

$K E_{\text {crit }} \quad=$ minimum kinetic energy that will cause a seal/flange leakage failure, $\mathrm{J}$

$m \quad=$ projectile mass

${ }^{1}$ Materials Research Engineer, Advanced Metallics Branch, 21000 Brookpark Road, non-member.

${ }^{2}$ Senior Technologist, Structures and Materials Division, 21000 Brookpark Road, AIAA Associate Fellow. 


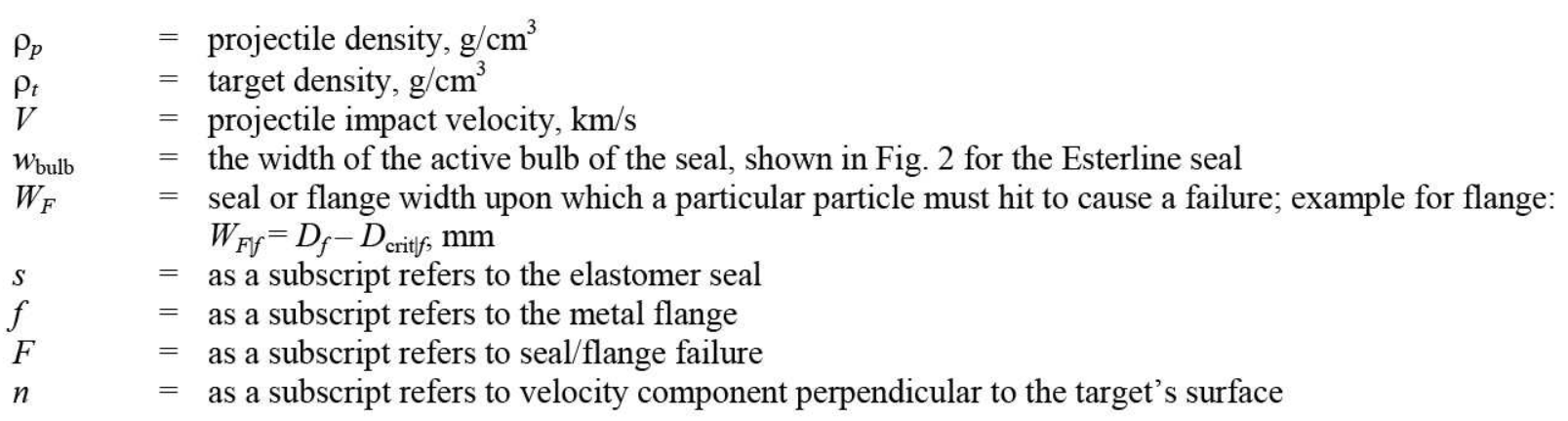

\section{Acronyms}

$\begin{array}{ll}\text { APAS } & =\text { Androgynous Peripheral Attachment System } \\ \text { ATLAS } & =\text { APAS To Low impact docking system Adaptor System } \\ \text { C-P } & =\text { Cour-Palais } \\ \text { CT } & =\text { Computed Tomography } \\ \text { CEV } & =\text { Crew Exploration Vehicle } \\ \text { ISS } & =\text { International Space Station } \\ \text { LIDS } & =\text { Low Impact Docking System } \\ \text { MMOD } & =\text { Micrometeoroid and Orbital Debris } \\ \text { NASA } & =\text { National Aeronautics and Space Administration } \\ \text { WSTF } & =\text { White Sands Test Facility }\end{array}$

\section{Introduction}

$\mathrm{N}$ ASA's Crew Exploration Vehicle (CEV) and the International Space Station (ISS) will be exposed to very high velocity impacts from micrometeoroids and orbital debris. ${ }^{1-6}$ The CEV will have a docking system which enables it to connect to ISS and other spacecraft and a hatch that opens so crew and supplies can pass between them. This docking system is known as the Low Impact Docking System (LIDS) and uses a silicone rubber seal to seal in cabin air. ${ }^{7}$ Figure 1 shows schematics of ISS, CEV, LIDS, and the LIDS main seal- which is a set of two concentric seals. Also shown in Fig. 1 is an artist's rendering of ATLAS (APAS To Low impact docking system Adaptor System, where APAS is the Androgynous Peripheral Attachment System) which is the docking/connecting element on ISS that docks with LIDS, sometimes referred to as the passive side of LIDS. The rubber seals on LIDS press against the aluminum flange on ATLAS. Prior to docking, both of these mating surfaces are exposed to the space environment. The main aspects of the space environment that cause damage to spacecraft are atomic oxygen, ultraviolet and ionizing radiations, and MMOD ${ }^{8}$ The effects of atomic oxygen, ultraviolet and ionizing radiations on the LIDS seals have been presented elsewhere, ${ }^{9}$ as have the probabilities of the seal and flange surfaces getting hit by MMOD. ${ }^{10}$

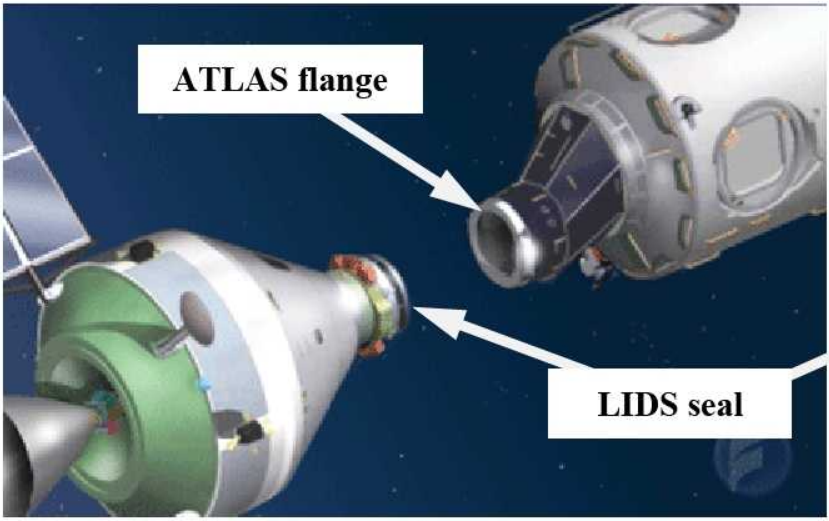

a)

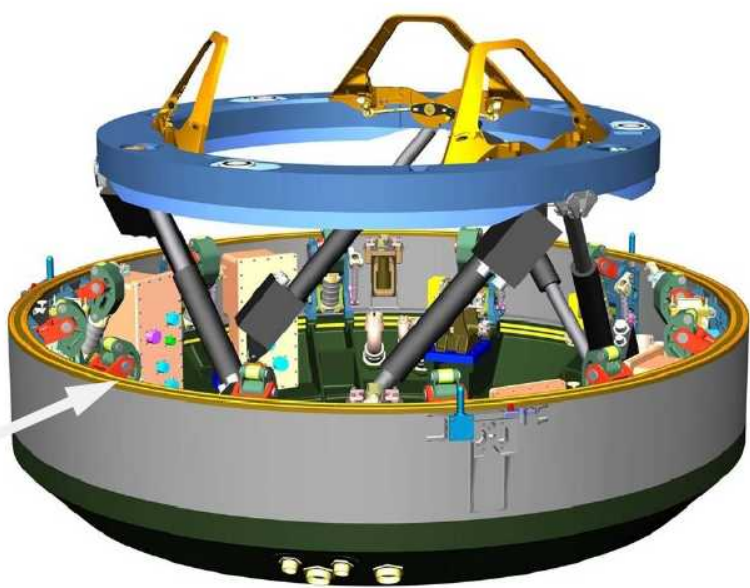

b)

Figure 1. ISS, CEV, LIDS and the LIDS seal. a) Artist's drawing of CEV docking to ATLAS which is connected to ISS; ${ }^{11}$ b) Schematic of LIDS and its primary seal which are located at the nose of CEV. 
The objective of this work is to quantify MMOD damage to silicone rubber seals and the metal surfaces these seals mate to, and determine how this damage affects seal performance. Impacts from the MMOD environment were simulated using ground based hypervelocity impacts. This paper presents our results of ground based hypervelocity impacts on silicone rubber seals and aluminum sheet plates along with leakage testing of damaged seal and plates.

Although silicone based seals have been used extensively by NASA, ${ }^{12}$ we have not found applicable hypervelocity impact studies for elastomers prior to the work presented here. Related work has typically concentrated on modeling the MMOD environment, ${ }^{3,13-16}$ or on metal, glass, or composite targets, or on the depth of penetration of the hypervelocity projectile, rather than the diameter of the crater and characteristics of the crater's crown (the area around the crater that is raised above the surface of the substrate) ${ }^{3,17-19}$ Many estimates of crater size or depth begin with Cour-Palais type relations. ${ }^{3,14,17}$ which are applicable to the threshold penetration of single, thin, ductile metal plates. Such Cour-Palais penetration relations are not directly applicable to our case since those treatments concentrate on projectile penetration depth, where as we are considering elastomers instead of ductile metals, relatively thick targets, and have a failure mode that is dominated by the surface diameter of the crater and crown morphology. Our seals generally fail one of three ways. The first failure mode is when the projectile makes a crater in the elastomer that spans the width of the seal. The second is when the diameter of the crater in the metal surface, upon which the seal is to mate, spans the width of the seal. The third failure mode is when the crown of the crater is very tall or has "rolled over" making a tube, or protected area, that the seal cannot seal over. The depth of projectile penetration found through Cour-Palais type data and analysis is not equal to the crater's diameter in-plane with the target's surface. However, prior work has shown that for projectiles and targets of the same material, at sufficiently high velocities, the in-plane diameter of a crater is close to two times the depth of the crater. ${ }^{20,21}$ CourPalais estimates (with the adoption of this semi-spherical convention) and other scaling laws, ${ }^{22}$ will be compared to recent hypervelocity tests in aluminum and silicone based elastomers. Horz et al. ${ }^{23}$ have presented very detailed measurements of crater depth, diameters and details associated with crowns made in aluminum targets; the works of Christiansen, ${ }^{24}$ Cour-Palais ${ }^{16}$ and Watts ${ }^{25}$ are also reviewed in Horz's paper.

Elastomer seals made of two silicone based elastomer compounds were impacted with hypervelocity particles. The leak rate of these seals was tested before and after impacts. To examine how the seals will perform with a flange that might be damaged from MMOD, $6 \mathrm{~mm}$ thick aluminum alloy plates were impacted, then an undamaged seal placed over the impact crater and leak tested.

We present in this paper the reasoning and experiment procedures used in the design and manufacture of the small scale seals used to mimic the LIDS docking seal, the hypervelocity test methods, and the measurements made of the damaged seals and metal plates in terms of physical damage and resulting leakage. Although the number of impact tests was limited, the projectile's incidence angle, speed, mass, and density were varied in an effort to determine what effects these might have on damage. Most impacts were done near room temperature, but some impacts were done with elastomer targets cooled to near $-78^{\circ} \mathrm{C}$, which is roughly equal to the coldest non-operating temperature of $-75{ }^{\circ} \mathrm{C}$ for the LIDS seals. ${ }^{26}$ Trends are developed so that this work might extend to other seals exposed to the space environment and thereby enable their failures due to MMOD damage to be predicted.

\section{Procedure}

\section{A. Hypervelocity Impacts}

1. Targets

Hypervelocity impacts of elastomer and aluminum alloy targets were done at White Sands Test Facility in New Mexico. ${ }^{27}$ The two peroxide cured, silicone based elastomer compounds were Parker's S0383-70, and Esterline's ELA-SA-401. Parker's S0383-70 is rust colored with a Shore A hardness of 70; Esterline's ELA-SA-401 is blond with a hardness of about 40 . The relevant properties of the elastomers are approximately: density $=1.15 \mathrm{~g} / \mathrm{cm}^{3}$; tensile strength $=8 \mathrm{MPa}$; and speed of sound $=984 \mathrm{~m} / \mathrm{s}$. The $6061-\mathrm{T} 651$ aluminum targets were $178 \times 178 \mathrm{x}$ $6.35 \mathrm{~mm}$ thick $(7 \times 7 \times 1 / 4 \mathrm{in}$.) with a surface finish of $0.4 \mu \mathrm{m}(15 \mu \mathrm{in}$.). Elastomer targets were tested in the "as received condition", and after a treatment of atomic oxygen. Atomic oxygen treatments are used to form a $\mathrm{SiO}_{\mathrm{x}}$ rich surface layer to decrease the adhesive properties of the elastomers. ${ }^{28}$ Aluminum targets were tested as received, anodized (MIL-A-8625, Type II, Class 1), and after receiving a $0.013 \mathrm{~mm}(0.0005$ in.) thick coating of electroless nickel (AMS-C-26074, Class 4, Grade A). The properties of the $6061 \mathrm{~T} 651$ targets relevant to hypervelocity impacts were: density $=2.7 \mathrm{~g} / \mathrm{cm}^{3}$, Brinell Hardness $=95$; ultimate tensile strength $=310 \mathrm{MPa}$; and speed of sound $=$ $6400 \mathrm{~m} / \mathrm{s}$. It is expected that the flanges on ISS to which LIDS will mate will be aluminum alloy, either anodized, or perhaps coated with nickel for electrical conductivity reasons.

Two basic LIDS seal designs are being examined; both designs have two concentric seals for redundancy. The Parker seal, known as a Gask-O-Seal, has relatively narrow bulbs while the Esterline seal, known as 
Esterline/NASA 2-piece seal, has wider seal pads. Figure 2 shows scaled down versions of the LIDS seals we are testing, and schematics of their cross sections. In hypervelocity tests, the LIDS seal designs were mimicked using seals of similar bulb width and height cut from $5.5 \mathrm{~mm}$ thick sheet material of the same elastomer compound using a water-knife. At the time impact tests were started, no small scale Gask-O-Seals or Esterline 2-piece seals were available. About $70 \%$ of the time the projectile successfully hit the target; about $30 \%$ of the time the projectile missed, nearly missed, or the test failed due to some other problem. We are in the process now of impacting small scale engineering seals. Figure 3 shows examples of the seals used in this study. In addition to these, a couple tests impacted a $3.2 \mathrm{~mm}(1 / 8 \mathrm{in}$.) thick aluminum plate coated with a $0.51 \mathrm{~mm}$ thick layer of the Parker S0383-70 compound simulating the web material at the base of the Gask-O-Seal trough. The layer of elastomer was bonded to the plate by Parker using the same methods they use in the production of Gask-O-Seals.

A few tests were done with seals tilted at either $45^{\circ}$ or $60^{\circ}$ (where $0^{\circ}$ is perpendicular to the target surface). As the seal is tilted, the top surface of the seal becomes increasingly difficult to hit. Thus only a small number of impacts with the seal tilted were done. Impacts done at an angle were set up such that the path of the projectile was parallel to the seal's major radius, coming from the seal's center, towards its outer diameter.

During flight operations the orbiter is often flown in a particular orientation to the Sun so that the temperature of specific parts of the orbiter can be controlled. While the engines of CEV are flown facing the Sun, the LIDS seals at the nose can get quite cold. Others have estimated the minimum temperature of LIDS near the seals to be $-78{ }^{\circ} \mathrm{C}$ $\left(-105^{\circ} \mathrm{F}\right) .^{29}$ Tests were done with the plate upon which the seals were mounted chilled so that the temperature of the seal being impacted, as measured by a thermocouple imbedded in the rubber, was $-78{ }^{\circ} \mathrm{C} \pm 5{ }^{\circ} \mathrm{C}$. The maximum "survival" temperature expected for the LIDS seals during flight operations is $125^{\circ} \mathrm{C}\left(257^{\circ} \mathrm{F}\right)$; impact tests at this higher temperature are planned.

2. Projectiles

During missions the seals are threatened by both meteoroids and orbital debris while undocked. Debris is prevalent in LEO, but decreases as orbital altitude increases. The average velocity of debris is between 7 and $8 \mathrm{~km} / \mathrm{s}$ for particles between 0.01 and $1 \mathrm{~cm}$ respectively. The average velocity of micrometeoroids is about $20 \mathrm{~km} / \mathrm{s} .{ }^{3,30}$ The density of orbital debris varies, but a good approximation of the average density of debris is $2.7 \mathrm{~g} / \mathrm{cm}^{3}$, the density of

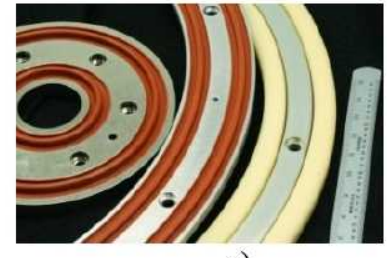

a)

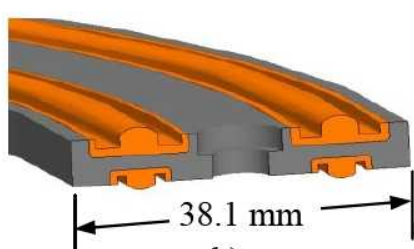

b)

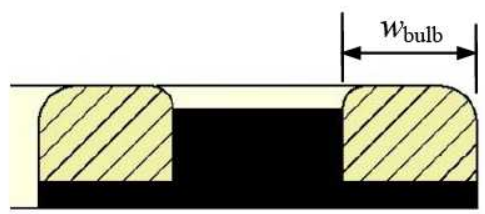

c)

Figure 2. Parker Gask-O-Seal, and Esterline/NASA 2-piece seals. a) shows a $10 \mathrm{~cm}$ (4 in.) diameter Parker Gask-O-Seal, a $30.5 \mathrm{~cm}$ (12 in.) diameter Parker seal, and the Esterline seal with $9.1 \mathrm{~mm}$ wide seal beads (blond); b) schematic of the Parker Gask-O-Seal cross section with the width of the seal area shown; c) schematic of the Esterline/NASA 2-piece seal with $w_{\text {bulb }}$ labeled.

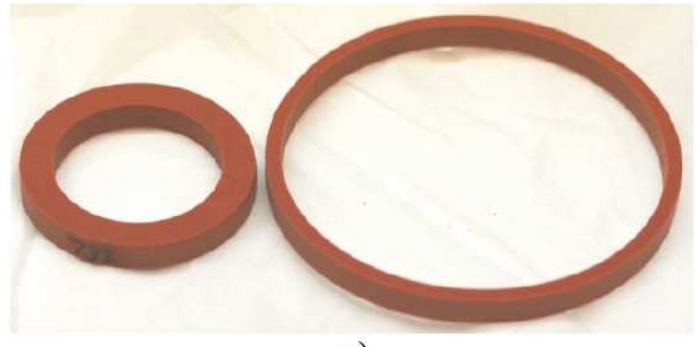

a)

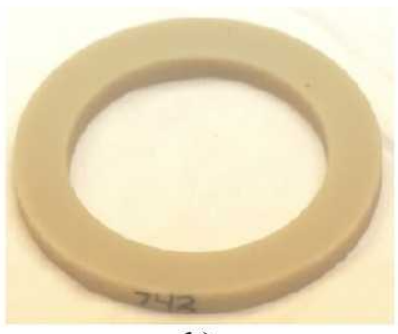

b)

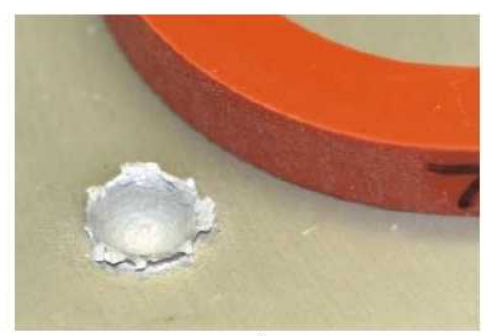

c)

Figure 3. Test articles used in hypervelocity impact tests. a) $5.2 \mathrm{~mm}$ and $2.5 \mathrm{~mm}$ wide Parker "ring" seals; b) $9.1 \mathrm{~mm}$ wide Esterline "ring" seal; c) anodized aluminum plate cratered by a $1 \mathrm{~mm}$ diameter, $1.4 \mathrm{mg}$, $8 \mathrm{~km} / \mathrm{s}$ aluminum projectile and a $5.1 \mathrm{~mm}$ wide Parker seal. 
aluminum. ${ }^{15,30}$ Although rocky and iron-rich meteoroids exist, meteoroids are primarily made of ice. Thus a density of $1 \mathrm{~g} / \mathrm{cm}^{3}$ is considered a good estimate of meteoroid density. ${ }^{31}$ The velocities characteristic of meteoroids exceed current ground based hypervelocity impact capabilities. However, velocities characteristic of debris $(7.5 \mathrm{~km} / \mathrm{s})$ can be well matched by facilities at White Sands Test Facility (WSTF). Densities of projectiles can also be well matched in labs. Three different materials were used as projectiles, all were in the form of spheres:

- 2017 T4 Grade 200 aluminum, density $=2.79 \mathrm{~g} / \mathrm{cm}^{3}$, hardness $105 \mathrm{HB}$. These are ball bearings with a fairly high hardness for aluminum alloys. Variations in the copper content of this alloy can be expected to cause density variation of about $\pm 1 \%$.

- Dry soda lime glass, density $=2.5 \pm 0.1 \mathrm{~g} / \mathrm{cm}^{3}$. These are 9000 Series, NIST Traceable Particle Size Standards from Thermo Scientific, with a Moh hardness of about 6.5 and a Young's modulus of about $10 \times 10^{6} \mathrm{psi}$. The sizes we used $(0.4$ and $1 \mathrm{~mm})$ had a size distribution standard deviation of $3 \%$.

- Nylon66, density $=1.14 \mathrm{~g} / \mathrm{cm}^{3}$.

\section{Hypervelocity Impacts}

Hypervelocity impacts were performed at the White Sands Test Facility (WSTF) Remote Hypervelocity Test Laboratory (RHTL) in Las Cruces, New Mexico, using their .17-caliber Light Gas Gun. ${ }^{27}$ This system verifies the condition of the projectile and measures particle velocity using ultra-high speed digital imaging SIM cameras manufactured by Photo-Sonics Inc.. Projectile velocity is also measured with laser intervalometer and photodiode flash detector stations. Maximum velocities available were about $8.3 \mathrm{~km} / \mathrm{s}$; tests at between 5 and $8.3 \mathrm{~km} / \mathrm{s}$ were done. The velocity goal for most tests was $8.2 \mathrm{~km} / \mathrm{s}$. Figure 4 shows ultra-high speed images from the SIM cameras for Strike 12 which was a $1 \mathrm{~mm}$ diameter, $1.46 \mathrm{mg}$ aluminum sphere striking an anodized aluminum target at $8.03 \mathrm{~km} / \mathrm{s}$. The images are $2.1 \mu \mathrm{s}$ apart, and the exposure time of each frame is $30 \mathrm{~ns}$. Figure 5 shows ultra-high speed images of Strike 2, a hit onto the Parker elastomer using a $0.7 \mathrm{~mm}$ diameter, $0.50 \mathrm{mg}$ aluminum sphere at $8.17 \mathrm{~km} / \mathrm{s}$.

Table 1 presents the hypervelocity tests accomplished and used in this study to determine crater diameters and seal failures resulting from various projectiles. The Strike No. and Specimen ID are included to assist with traceability. The mass of the projectile provided was calculated based on the shape (spherical), diameter, and density of the particle.

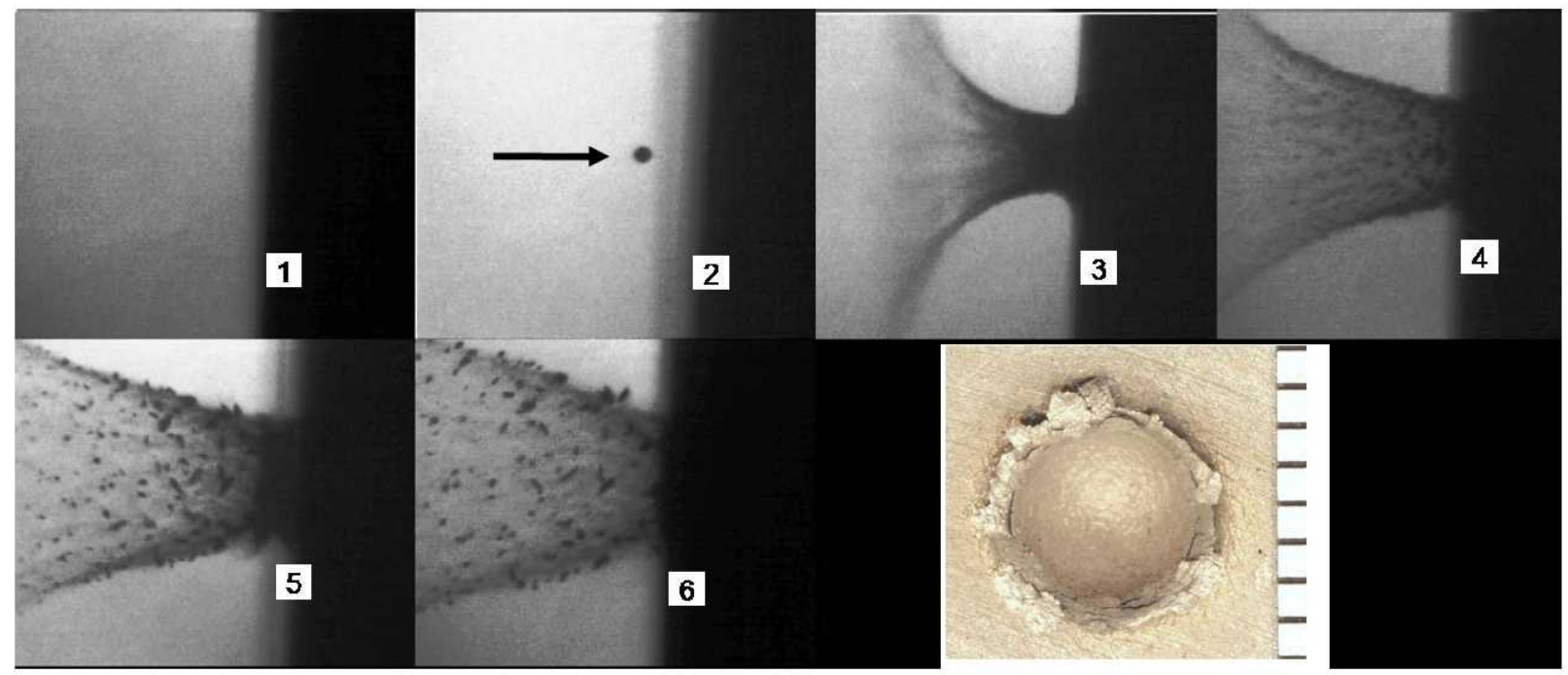

Figure 4. Ultra-high speed images of Strike 12. $2.1 \mu$ s between images, exposure time was 30 ns. Aluminum target hit by a $1 \mathrm{~mm}$ dia., $1.46 \mathrm{mg}, 8.03 \mathrm{~km} / \mathrm{s}$ aluminum projectile. Note the raised crater rim material due to the energetic hit. 


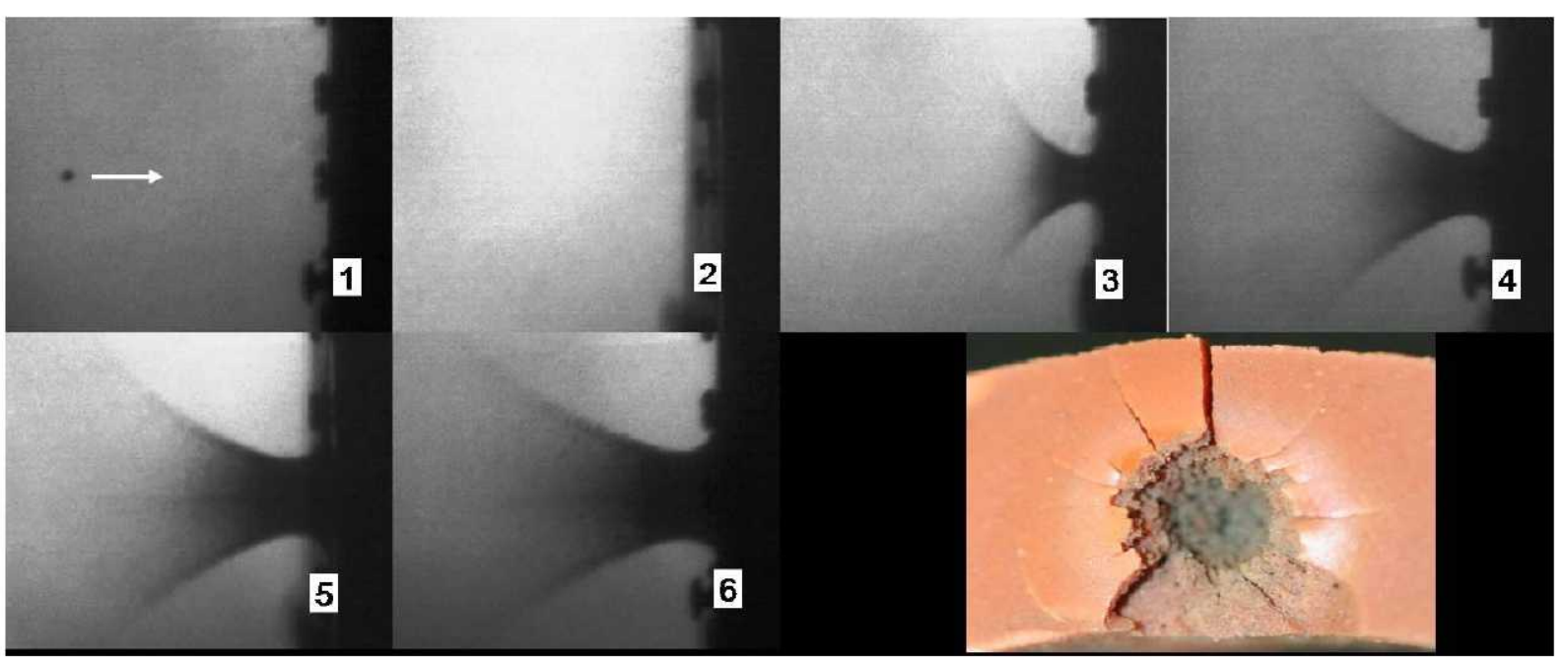

Figure 5. Ultra-high speed images of Strike 2. $2.1 \mu$ s between images, exposure time was $30 \mathrm{~ns}$. Parker elastomer target hit by a $0.7 \mathrm{~mm}$ dia., $0.50 \mathrm{mg}, 8.17 \mathrm{~km} / \mathrm{s}$ aluminum projectile. This damaged seal did not leak significantly.

\section{B. Crater Measurements}

Several measurements of damaged areas in the elastomer and aluminum alloy targets were made. From these measurements an average crater diameter, $D_{\text {seal }}$ or $\mathrm{D}_{f}$, was calculated. If the crater was elliptical, the diameter was set to the arithmetic average of the ellipse's major and minor axes.

For the elastomers, five measurements were made:

1) $d_{v}$ : The average maximum diameter of the vaporized void at the center of the crater. An example of a crater in one of the elastomers tested is provided in Fig. 6. It can be seen in the cross sectional view made by computed tomography (CT) provided in Fig. 6 b) that the maximum diameter of the vaporized void is, in this case, larger than the entry hole. $d_{v}$ was measured using optical photographs and close inspection of the crater and the level of undercutting. Figure 7 shows $d_{v}$ drawn on a crater in a Parker seal.

2) $d_{\text {min }}$ : The average minimum diameter of the crater, sometimes referred to as the entry hole.

3) $d_{s}$ : The average diameter of secondary damage, such as a region, or secondary crater, created by chunks of the surface being blown off, as show in Fig. 7. If there was no significant secondary damage, or if its diameter was less than $d_{v}, d_{s}$ was set equal to $d_{v}$. For example, there is no significant secondary damage in the Esterline seal shown in Fig. 6 ; in this case, $d_{s}$ would be set equal to $d_{v}$.

4) $d_{c}$ : The average diameter of the cracked region, as shown in Figs. 6 and 7.

The average diameter of the crater in the elastomer, $D_{\text {seal }}$, was defined as the average of $d_{v}, d_{s}$, and $d_{c}$ (i.e., $\left.D_{\text {seal }}=\left(d_{v}+d_{s}+d_{c}\right) / 3\right)$.

5) The hit location of the projectile was quantified and defined by the surface distance between the crater's center and the center-line of the seal, denoted $c-c$, (where the center-line of the seal is defined as the circumferential line midway between the seal's inner and outer diameters). This distance between the crater's center and seal's center-line, $c-c$, is also used in the testing of undamaged seals over cratered metal targets. Values of $c-c$ are negative if the crater is closer to the seal's inner wall, positive if the crater is located nearer the outer wall of the seal, and $c-c$ $=0$ if the center of the crater is at the seal's center-line. 
Table 1. Projectiles, targets and velocities used in impact tests. Targets were Parker S0383-70, Esterline ELA-SA-401, 6061 T651 aluminum, or the aluminum coated with a $0.51 \mathrm{~mm}$ thick layer of the Parker elastomer. Pre-treatment notes exposure to atomic oxygen, or a coating on the aluminum. Mass was calculated based on density and diameter. All projectiles were spherical. Aluminum projectiles were 2017 T4 grade 200 ball bearings, $\rho_{p}=2.79 \mathrm{~g} / \mathrm{cm}^{3}$; Glass projectiles were 9000 Series soda lime glass size standards, $\rho_{p}=2.5 \mathrm{~g} / \mathrm{cm}^{3}$; Nylon 66 had a density of $1.14 \mathrm{~g} / \mathrm{cm}^{3}$; the steel projectile was $440 \mathrm{C}$ stainless, $\rho_{p}=7.7 \mathrm{~g} / \mathrm{cm}^{3}$. Strikes $35 \mathrm{c}, 35 \mathrm{~d}, 37$ and $38 \mathrm{~b}$ were done with the target cooled to $-78{ }^{\circ} \mathrm{C}\left(-108{ }^{\circ} \mathrm{F}\right)$.

\begin{tabular}{|c|c|c|c|c|c|c|c|c|}
\hline $\begin{array}{l}\text { Strike } \\
\text { no. }\end{array}$ & $\begin{array}{c}\text { Target } \\
\text { material }\end{array}$ & $\begin{array}{c}\text { Target } \\
\text { pre-treatment, } \\
\mathrm{AO}: \text { atoms } / \mathrm{cm}^{2} \\
\text { or coating }\end{array}$ & $\begin{array}{c}\text { Target width } \\
\text { or thickness, } \\
\mathrm{mm}\end{array}$ & $\begin{array}{c}\text { Angle, } \\
\text { degrees } \\
\text { off } \\
\text { vertical }\end{array}$ & $\begin{array}{c}\text { Mass, } \\
\text { mg }\end{array}$ & $\begin{array}{c}\text { Projectile } \\
\text { diameter, } \\
\mathrm{mm}\end{array}$ & $\begin{array}{c}\text { Projectile } \\
\text { density, } \\
\text { g/cc }\end{array}$ & $\begin{array}{c}\text { Velocity, } \\
\mathrm{km} / \mathrm{s}\end{array}$ \\
\hline 31 & Parker & As received & 2.5 wide & 0 & 0.093 & 0.4 & 2.79 & 7.57 \\
\hline 29 & Parker & $8.0 \mathrm{E}+19$ & 2.5 wide & 0 & 0.093 & 0.4 & 2.79 & 5.75 \\
\hline 9 & Parker & $8.0 \mathrm{E}+19$ & 2.5 wide & 0 & 0.078 & 0.391 & 2.5 & 8.19 \\
\hline $35 \mathrm{c}$ & Parker $-78^{\circ} \mathrm{C}$ & $1.0 \mathrm{E}+20$ & 2.5 wide & 0 & 0.093 & 0.4 & 2.79 & 7.8 \\
\hline 17 & Parker & $1.0 \mathrm{E}+20$ & 2.5 wide & 45 & 0.093 & 0.4 & 2.79 & 7.93 \\
\hline $35 \mathrm{~d}$ & Parker $-78^{\circ} \mathrm{C}$ & $1.2 \mathrm{E}+20$ & 2.5 wide & 0 & 0.093 & 0.4 & 2.79 & 8.22 \\
\hline 15 & Parker & $1.0 \mathrm{E}+20$ & 2.5 wide & 0 & 0.183 & 0.5 & 2.79 & 8.04 \\
\hline 37 & Parker $-78^{\circ} \mathrm{C}$ & $1.2 \mathrm{E}+20$ & 2.5 wide & 0 & 0.183 & 0.5 & 2.79 & 8.29 \\
\hline 6 & Parker & $8.0 \mathrm{E}+19$ & 2.5 wide & 0 & 0.316 & 0.6 & 2.79 & 8.22 \\
\hline $6 \mathrm{~b}$ & Parker & $8.0 \mathrm{E}+19$ & 2.5 wide & 0 & 0.316 & 0.6 & 2.79 & 8.26 \\
\hline 2 & Parker & $7.5 \mathrm{E}+20$ & 5.2 wide & 0 & 0.501 & 0.7 & 2.79 & 8.17 \\
\hline $7 \mathrm{~d}$ & Parker & $3.5 \mathrm{E}+20$ & 5.2 wide & 60 & 0.748 & 0.8 & 2.79 & 8.27 \\
\hline $7 \mathrm{c}$ & Parker & $7.5 \mathrm{E}+20$ & 5.2 wide & 60 & 0.748 & 0.8 & 2.79 & 8.29 \\
\hline $7 \mathrm{f}$ & Parker & $3.5 \mathrm{E}+20$ & 5.2 wide & 60 & 0.805 & 0.82 & 2.79 & 8.24 \\
\hline 8 & Parker & $1.0 \mathrm{E}+20$ & 5.2 wide & 45 & 3.209 & 1.3 & 2.79 & 8.34 \\
\hline 21 & Parker/Al & As received & 0.5 on 3 thick & 0 & 0.093 & 0.4 & 2.79 & 8.24 \\
\hline 22 & Parker/Al & As received & 0.5 on 3 thick & 60 & 0.748 & 0.8 & 2.79 & 8.19 \\
\hline 30 & Esterline & As received & 9.1 wide & 0 & 1.461 & 1 & 2.79 & 5.56 \\
\hline 32 & Esterline & As received & 9.1 wide & 0 & 1.461 & 1 & 2.79 & 7.47 \\
\hline $5 b$ & Esterline & As received & 9.1 wide & 45 & 7.177 & 1.7 & 2.79 & 8.1 \\
\hline 3 & Esterline & $3.4 \mathrm{E}+20$ & 9.1 wide & 60 & 0.501 & 0.7 & 2.79 & 8.21 \\
\hline 1 & Esterline & $7.0 \mathrm{E}+20$ & 9.1 wide & 0 & 0.748 & 0.8 & 2.79 & 8.3 \\
\hline 18 & Esterline & $1.0 \mathrm{E}+20$ & 9.1 wide & 0 & 1.031 & 1.2 & 1.14 & 7.84 \\
\hline 36 & Esterline & $1.5 \mathrm{E}+20$ & 9.1 wide & 0 & 1.461 & 1 & 2.79 & 7.56 \\
\hline 10 & Esterline & $1.0 \mathrm{E}+20$ & 9.1 wide & 0 & 1.771 & 1.106 & 2.5 & 8.38 \\
\hline $4 \mathrm{c}$ & Esterline & $3.4 \mathrm{E}+20$ & 9.1 wide & 0 & 1.461 & 1 & 2.79 & 8.19 \\
\hline 16 & Esterline & $1.0 \mathrm{E}+20$ & 9.1 wide & 0 & 2.096 & 1.52 & 1.14 & 7.61 \\
\hline $38 \mathrm{~b}$ & Esterline $-74^{\circ} \mathrm{C}$ & $1.5 \mathrm{E}+20$ & 9.1 wide & 45 & 3.209 & 1.3 & 2.79 & 7.95 \\
\hline $8 \mathrm{c}$ & Esterline & $7.0 \mathrm{E}+20$ & 9.1 wide & 45 & 3.209 & 1.3 & 2.79 & 8.24 \\
\hline 14 & $\mathrm{Al}$ & As received & 6.3 thick & 0 & 0.093 & 0.4 & 2.79 & 7.96 \\
\hline 23 & $\mathrm{Al}$ & As received & 6.3 thick & 0 & 5.984 & 1.6 & 2.79 & 7.9 \\
\hline 13 & $\mathrm{Al}$ & Anodized & 6.3 thick & 0 & 0.183 & 0.5 & 2.79 & 8.14 \\
\hline 12 & $\mathrm{Al}$ & Anodized & 6.3 thick & 0 & 1.461 & 1 & 2.79 & 8.03 \\
\hline 19 & $\mathrm{Al}$ & Anodized & 6.3 thick & 0 & 5.762 & 1.58 & 2.79 & 7.9 \\
\hline 11 & $\mathrm{Al}$ & Anodized & 6.3 thick & 0 & 11.687 & 2 & 2.79 & 7.65 \\
\hline 40 & $\mathrm{Al}$ & Ni coated & 6.3 thick & 45 & 0.093 & 0.4 & 2.79 & 7.5 \\
\hline $39 \mathrm{~b}$ & $\mathrm{Al}$ & Ni coated & 6.3 thick & 0 & 0.093 & 0.4 & 2.79 & 8.34 \\
\hline 50 & Stainless & As received & 3.0 thick & 0 & 0.504 & 0.5 & 7.7 & 7.6 \\
\hline
\end{tabular}




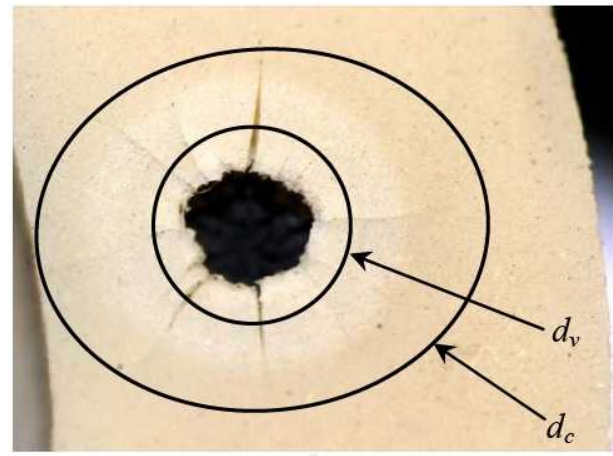

a)

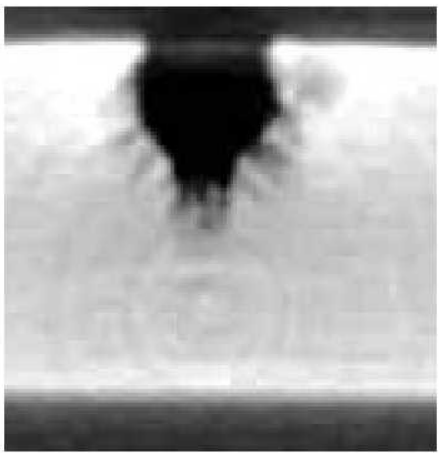

b)

Figure 6. Cratered Esterline seal. a) Top view of the $9.1 \mathrm{~mm}$ wide Esterline seal damaged by a $0.8 \mathrm{~mm}$ diameter, $0.728 \mathrm{mg} \mathrm{Al}$ sphere at $8.3 \mathrm{~km} / \mathrm{s}$, Strike 1; the black ellipses show $d_{c}$ - the extent of cracks radiating from the crater, and $d_{v}$-the diameter of the vaporized material; b) Cross sectional view of the crater using computed tomography, seal is $5.5 \mathrm{~mm}$ thick, Strike 1.

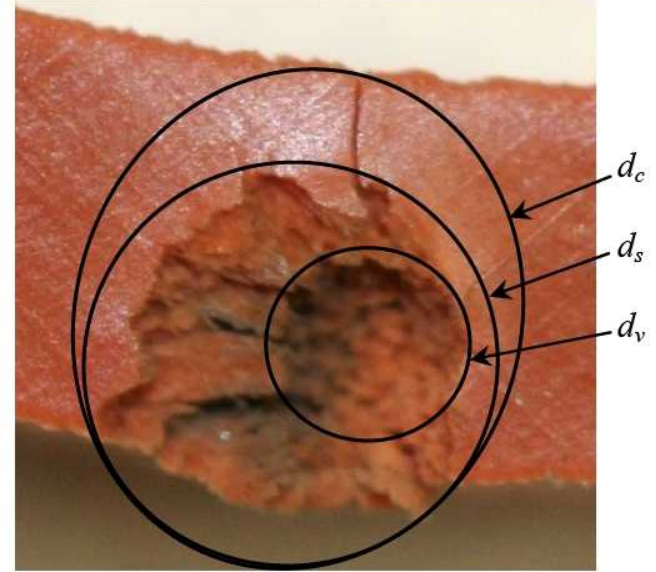

Figure 7. Cratered Parker seal. Strike 17, Parker $2.5 \mathrm{~mm}$ wide seal, hit by a $0.4 \mathrm{~mm}$ diameter, $0.093 \mathrm{mg}$ aluminum sphere at $7.93 \mathrm{~km} / \mathrm{s}$, with the crater diameters $d_{v}, d_{s}$, and $d_{s}$ shown.

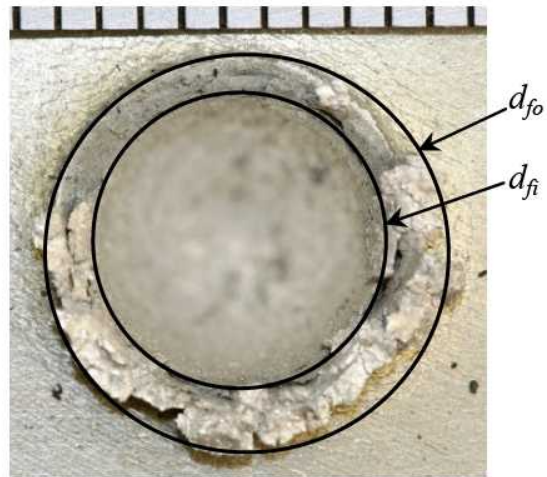

Figure 8. Cratered aluminum plate. Strike 19, anodized $6061 \mathrm{~T} 651$ aluminum alloy plate hit by a $1.58 \mathrm{~mm}$ diameter, $5.76 \mathrm{mg}$, aluminum sphere at $7.9 \mathrm{~km} / \mathrm{s}$; black circles show the inner diameter, $d_{f i}$, and outer diameter, $d_{f o}$; a mm scale is at the top of the image.

For the metal targets representing the flange with which the seals mate, three measurements were made:

1) $d_{f i}$ : The average inner diameter of the metal crater. This measurement was taken from an image of the crater by placing a circle (or ellipse) around the crater near its inflection point, near where the crater meets the plane of the target's surface, as shown in Fig. 8.

2) $d_{f o}$ : The average outer diameter of the metal crater. This measurement was taken from an image of the crater by placing a circle (or ellipse) around the outer edges of the crater's crown, as shown in Fig. 8.

3) $h$ : The average height of the crown of the crater above the target's surface. Several measurements were taken of the height of the crater around is circumference and averaged. Measurements were made using a side view image of the crater with a scale placed near the crown.

The average crater diameter in metal targets, $D_{f}$, was the average of $d_{f i}$ and $d_{f o}$ (i.e. $\left.D_{f}=\left(d_{f i}+d_{f o}\right) / 2\right)$ 


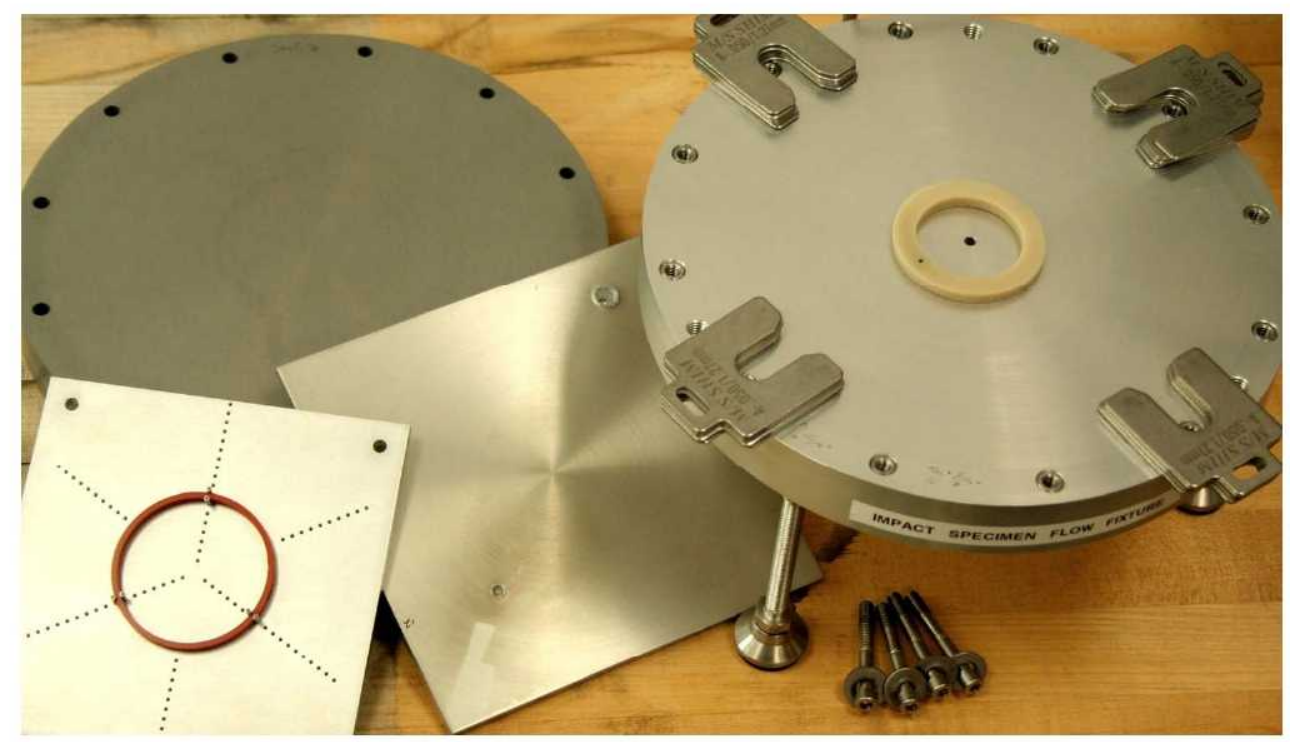

Figure 9. Impact Specimen Flow Fixture. Tapped $15.2 \mathbf{c m}^{2}$ plate has a Parker seal mounted; metal flange: $17.8 \mathrm{~cm}^{2}$ plate has two craters in it; bottom flow fixture plate shown with an Esterline seal ring with a small crater.

\section{Seal Leakage}

Elastomer seals and aluminum alloy plates damaged by hypervelocity projectiles were leak tested in a fixture known as the Impact Specimen Flow Fixture. ${ }^{32}$ Seals were compressed between flat plates separated by shims, $25 \%$ of the seal ring height and the space between them pressurized to 1 atmosphere above the pressure in the room. After pressurization input valves were closed and the system monitored for leakage for between 2 and 16 hours via a pressure decay method with accurate pressure and temperature measurements. Figure 9 shows several elements of the test hardware: the lower plate of the flow test fixture with an Esterline seal damaged by an impact on the system's bottom plate; a plate used to hold and position Parker seals during impact testing at White Sands with a Parker seal mounted; and an impact damaged aluminum plate.

In the testing of cratered aluminum plates, an undamaged seal was used and the crater placed at various locations across the width of the seal. The placement of the crater over and onto the seal was done carefully by eye. Then, after the test was finished, the heavy top plate and cratered plate were removed and the location of the crater measured from the imprint of the crater on the rubber; various magnifying glasses were often used to help with this measurement. The location of the crater is defined as, $c-c$, the distance between the center of the crater and the center-line of the seal. The uncertainty of this $c-c$ measurement is judged to be $\pm 0.1 \mathrm{~mm}$. In some cases there was a dimple on the back side of the plate from the impact. In such situations shims were used to prevent the top plate from pressing on the dimple and to maintain the plates parallel. In some cases the plate was perforated. In these cases an o-ring was placed on the back side of the plate around the perforation and shims used to achieve good compression and separation of the top and impacted plates. A test of this seal around the perforation was done prior to testing over a crater to make sure any leakage during a test was coming from the cratered, crown side only.

Seals and plates were hit with particles of various kinetic energies, and then leak tested. In this way $D_{\text {crit }}$ and the minimum kinetic energy required to cause seal failure was found for four cases: damaged Parker and Esterline seals against undamaged aluminum, and damaged aluminum pressed against undamaged Parker and Esterline seals. A seal/flange failure was defined as leakage equal to or greater than $0.001 \mathrm{~kg}$ air $/$ day. Once $D_{\text {crit }}$ and the relation between projectile kinetic energy, $K E$, and resulting crater size are found, the width of the seal or flange area susceptible to failure, $W_{F}$, due to a hit from a particular particle can be determined. The development and use of $W_{F}$ is presented in a companion paper by de Groh et al. ${ }^{10}$

\section{Results}

Measurements made on damaged plates and seals are presented in Tables 2, 3, and 4. The maximum leakage allowed for the whole CEV spacecraft is about $0.01 \mathrm{~kg}$ air/day. The maximum leakage allocated for the LIDS seal is about $0.001 \mathrm{~kg}$ air/day. We chose $0.001 \mathrm{~kg}$ air/day as the leakage failure criteria corresponding to a Loss of Mission objective. 
Table 2. Surface Diameters and Crown Heights of Craters in Flange Materials. Kinetic energy based on projectile speed, not the velocity component normal to the target's surface. Leakage column indicates seal pass or failure for the $2.5 \mathrm{~mm}$ wide Parker seal $(P)$, or the $9.1 \mathrm{~mm}$ wide Esterline $(E)$ seal.

\begin{tabular}{c|c|c|c|c|c|c|c|c|c}
\hline $\begin{array}{c}\text { Strike } \\
\text { no. }\end{array}$ & $\begin{array}{c}\text { Mass, } \\
\mathrm{mg}\end{array}$ & $\begin{array}{c}\text { Velocity, } \\
\mathrm{km} / \mathrm{s}\end{array}$ & $\begin{array}{c}\text { Kinetic } \\
\text { energy, } \\
\mathrm{J}\end{array}$ & $\begin{array}{c}\text { Crater } \\
\mathrm{ID}, \\
d_{f,}, \\
\mathrm{~mm}\end{array}$ & $\begin{array}{c}\text { Crater } \\
\text { OD, } \\
d_{f o}, \\
\mathrm{~mm}\end{array}$ & $\begin{array}{c}D_{f,} \\
\mathrm{~mm}\end{array}$ & $\begin{array}{c}D_{f} / w_{\text {bulb, }}, \\
\%\end{array}$ & $\begin{array}{c}\text { Crown } \\
\text { height, } \\
h, \\
\mathrm{~mm}\end{array}$ & Leakage \\
\hline 40 & 0.093 & 7.5 & 2.63 & 1.46 & 1.73 & 1.59 & 64 & 0.255 & P-Pass \\
\hline 14 & 0.093 & 7.96 & 2.96 & 1.78 & 2.47 & 2.13 & 85 & 0.351 & P-Fail \\
\hline $39 \mathrm{~b}$ & 0.093 & 8.34 & 3.25 & 1.75 & 2.20 & 1.98 & 79 & 0.344 & P-Pass \\
\hline 13 & 0.183 & 8.14 & 6.05 & 2.20 & 2.82 & 2.51 & 100 & 0.42 & P-Fail \\
\hline 12 & 1.461 & 8.03 & 47.10 & 4.70 & 6.10 & 5.40 & 59 & 0.98 & E-Pass \\
\hline 19 & 5.762 & 7.9 & 179.80 & 7.02 & 9.57 & 8.30 & 91 & 1.50 & E-Fail \\
\hline 23 & 5.984 & 7.9 & 186.72 & 7.09 & 9.29 & 8.19 & 90 & 1.27 & E-Pass \\
\hline 11 & 11.687 & 7.65 & 341.97 & 9.30 & 10.80 & 10.05 & 110 & 1.00 & E-Fail \\
\hline 50 & 0.504 & 7.6 & 14.55 & 1.96 & 2.67 & 2.32 & & & \\
\hline \hline
\end{tabular}

Table 3. Diameters for Craters in Parker's S0383-70 elastomer. Kinetic energy is calculated using projectile velocity, not the velocity component perpendicular to the target. Strikes 2 and 7, boxed in bold, used wider Parker seals $(5.2 \mathrm{~mm})$, Strikes 21 and 22 were on large aluminum plates with a $0.5 \mathrm{~mm}$ thick coating of S0383-70, all other strikes were on $2.5 \mathrm{~mm}$ wide seals. See Table 1 for details on specific strikes. Accuracy of leakage flow measurements was typically $\pm 5 \times 10^{-6} \mathrm{~kg}$ air/day, leakage below this level is listed as $5 \times 10^{-6}$ $\mathrm{kg} /$ day. Seal failure is defined as leakage $>0.001 \mathrm{~kg}$ air/day. Shaded data was used in Fig. 17 and in the calculation of the $D_{\text {seal }}(K E)$ power law function. Strikes $35 \mathrm{c}, 35 \mathrm{~d}$, and 37 were at $-78^{\circ} \mathrm{C}$.

\begin{tabular}{c|c|c|c|c|c|c|c|c|c|c}
\hline $\begin{array}{c}\text { Strike } \\
\text { no. }\end{array}$ & $\begin{array}{c}\text { Mass, } \\
\mathrm{mg}\end{array}$ & $\begin{array}{c}\text { Velocity, } \\
\mathrm{km} / \mathrm{s}\end{array}$ & $\begin{array}{c}\text { Kinetic } \\
\text { energy, } \\
\mathrm{J}\end{array}$ & $\begin{array}{c}d_{v}, \\
\mathrm{~mm}\end{array}$ & $\begin{array}{c}d_{s}, \\
\mathrm{~mm}\end{array}$ & $\begin{array}{c}d_{c}, \\
\mathrm{~mm}\end{array}$ & $\begin{array}{c}D_{\text {seal, }} \\
\mathrm{mm}\end{array}$ & $\begin{array}{c}D_{\text {seal }} / w_{\text {bulb, }}, \\
\%\end{array}$ & $\begin{array}{c}\text { Distance } \\
\text { from seal's } \\
\text { center, } \\
c-c, \\
\mathrm{~mm}\end{array}$ & $\begin{array}{c}\text { Leakage, } \\
\mathrm{kg} / \text { day }\end{array}$ \\
\hline 29 & 0.093 & 5.75 & 1.55 & 1.07 & 1.89 & 2.6 & 1.853 & 74 & 0.18 & $5.0 \mathrm{E}-06$ \\
\hline 9 & 0.078 & 8.19 & 2.62 & 1.275 & 2.2 & 2.84 & 2.104 & 84 & 0.041 & 0.02 \\
\hline 31 & 0.093 & 7.57 & 2.68 & 0.68 & 0.97 & 1.08 & 0.911 & 36 & -1.06 & $5.0 \mathrm{E}-06$ \\
\hline $35 \mathrm{c}$ & 0.093 & 7.8 & 2.84 & 1.17 & 1.54 & 1.717 & 1.477 & 59 & 0.94 & $5.0 \mathrm{E}-06$ \\
\hline 17 & 0.093 & 7.93 & 2.94 & 1.14 & 2.44 & 2.8 & 2.127 & 85 & 0.38 & $5.0 \mathrm{E}-06$ \\
\hline $35 \mathrm{~d}$ & 0.093 & 8.22 & 3.16 & 1.125 & 1.63 & 1.76 & 1.505 & 60 & -0.69 & $5.0 \mathrm{E}-06$ \\
\hline 15 & 0.183 & 8.04 & 5.90 & 1.52 & 3.26 & 3.38 & 2.720 & 109 & -0.19 & 0.3 \\
\hline 37 & 0.183 & 8.29 & 6.27 & 1.86 & 3.27 & 3.36 & 2.830 & 113 & -0.3 & 0.1 \\
\hline 6 & 0.316 & 8.22 & 10.66 & 1.105 & 1.31 & 1.91 & 1.442 & 58 & 1.02 & $5.4 \mathrm{E}-06$ \\
\hline $6 \mathrm{~b}$ & 0.316 & 8.26 & 10.76 & 1.89 & 4.01 & 4.07 & 3.323 & 133 & 0.167 & 0.2 \\
\hline 2 & 0.501 & 8.17 & 16.72 & 2.37 & 4.69 & 6.43 & 4.497 & 86 & -0.4 & $5.0 \mathrm{E}-06$ \\
\hline $7 \mathrm{~d}$ & 0.748 & 8.27 & 25.58 & 3.06 & 4.52 & 7.75 & 5.110 & $\mathrm{n} / \mathrm{a}$ & $\mathrm{n} / \mathrm{a}$ & $5.0 \mathrm{E}-06$ \\
\hline $7 \mathrm{c}$ & 0.748 & 8.29 & 25.70 & 1.96 & 3.45 & 3.93 & 3.113 & 60 & 1.83 & $5.0 \mathrm{E}-06$ \\
\hline $7 \mathrm{f}$ & 0.805 & 8.24 & 27.34 & 2.46 & 5.27 & 6.2 & 4.643 & $\mathrm{n} / \mathrm{a}$ & $\mathrm{n} / \mathrm{a}$ & $5.0 \mathrm{E}-06$ \\
\hline 21 & 0.093 & 8.24 & 3.17 & 2.4 & 2.75 & 2.98 & 2.710 & $\mathrm{n} / \mathrm{a}$ & $\mathrm{n} / \mathrm{a}$ & \\
\hline 22 & 0.748 & 8.19 & 25.08 & 3.45 & 6 & 6.2 & 5.217 & $\mathrm{n} / \mathrm{a}$ & $\mathrm{n} / \mathrm{a}$ & \\
\hline \hline
\end{tabular}


Table 4. Diameters for Craters in Esterline's ELA-SA-401 Elastomer. Kinetic energy is calculated using projectile velocity, not the velocity component perpendicular to the target. See Table 1 for additional details on specific Strikes. Accuracy of leakage flow measurements was typically $\pm 5 \times 10^{-6} \mathrm{~kg}$ air/day, leakage below this level is listed as $5 \times 10^{-6} \mathrm{~kg} /$ day. Seal failure is defined as leakage $>0.001 \mathrm{~kg}$ air/day. Strikes shaded gray were used in $D_{\text {seal }}, K E$ power law analysis (Fig. 18); Strikes 36 and $38 \mathrm{~b}$ were at $-78^{\circ} \mathrm{C}$.

\begin{tabular}{c|c|c|c|c|c|c|c|c|c|c}
\hline $\begin{array}{c}\text { Strike } \\
\text { no. }\end{array}$ & $\begin{array}{c}\text { Mass, } \\
\mathrm{mg}\end{array}$ & $\begin{array}{c}\text { Velocity, } \\
\mathrm{km} / \mathrm{s}\end{array}$ & $\begin{array}{c}\text { Kinetic } \\
\text { energy, } \\
\mathrm{J}\end{array}$ & $\begin{array}{c}d_{v}, \\
\mathrm{~mm}\end{array}$ & $\begin{array}{c}d_{s}, \\
\mathrm{~mm}\end{array}$ & $\begin{array}{c}d_{c}, \\
\mathrm{~mm}\end{array}$ & $\begin{array}{c}D_{\text {seal }} \\
\mathrm{mm}\end{array}$ & $\begin{array}{c}D_{\text {seal }} / w_{\text {bulb, }} \\
\%\end{array}$ & $\begin{array}{c}\text { Distance } \\
\text { from seal's } \\
\text { center, } \\
c-c, \\
\mathrm{~mm}\end{array}$ & $\begin{array}{c}\text { Leakage, } \\
\mathrm{kg} / \mathrm{day}\end{array}$ \\
\hline 3 & 0.501 & 8.21 & 16.8871 & 2.95 & 4.506 & 4.81 & 4.09 & 45 & 2.3 & $5.0 \mathrm{E}-06$ \\
\hline 30 & 1.461 & 5.56 & 22.58 & 2.84 & 2.84 & 6.85 & 4.18 & 46 & 0.54 & $5.0 \mathrm{E}-06$ \\
\hline 1 & 0.748 & 8.3 & 25.7632 & 3.29 & 3.29 & 6.6 & 4.39 & 48 & -1.01 & $5.0 \mathrm{E}-06$ \\
\hline 18 & 1.031 & 7.84 & 31.6994 & 3.45 & 6.09 & 7.81 & 5.78 & 64 & 2.06 & $5.0 \mathrm{E}-06$ \\
\hline 32 & 1.461 & 7.47 & 40.7582 & 3.61 & 3.914 & 6.78 & 4.77 & 52 & 2.14 & $5.0 \mathrm{E}-06$ \\
\hline 36 & 1.461 & 7.56 & 41.7462 & 3.2 & 3.2 & 4.89 & 3.76 & 41 & 3.37 & $5.0 \mathrm{E}-06$ \\
\hline $4 \mathrm{c}$ & 1.461 & 8.19 & 48.9939 & 4.53 & 4.53 & 10.38 & 6.48 & 71 & 0 & $5.0 \mathrm{E}-06$ \\
\hline 16 & 2.096 & 7.61 & 60.698 & 4.23 & 8.49 & 10.12 & 7.61 & 84 & 0.187 & 0.3 \\
\hline 10 & 1.771 & 8.38 & 62.1837 & 3.18 & 4.78 & 10.07 & 6.01 & 66 & 0.7 & $5.0 \mathrm{E}-06$ \\
\hline 38b & 3.209 & 7.95 & 101.423 & 5.3 & 7.5 & 8.6 & 7.13 & 78 & 1.95 & $5.0 \mathrm{E}-06$ \\
\hline $8 \mathrm{c}$ & 3.209 & 8.24 & 108.958 & 5.2 & 8.7 & 10.87 & 8.26 & 91 & 1.8 & $5.0 \mathrm{E}-06$ \\
\hline 5b & 7.177 & 8.1 & 235.446 & 5.63 & 11.03 & 14.62 & 10.43 & 115 & -0.63 & 0.3 \\
\hline
\end{tabular}

\section{Aluminum Targets}

Table 2 presents results for 6061 aluminum plates, listing the strike number, the mass, velocity, and kinetic energy of the particle that hit the plate, the inner $\left(d_{f i}\right)$, outer $\left(d_{f o}\right)$ and average diameter of the "flange" crater $\left(D_{f}\right)$, the crater's crown height, $h$, and whether or not a seal was able to seal over the crater. The narrower Parker seal will not be able to seal over a crater in aluminum made by a particle with kinetic energy of 2.9 J or greater. The $9.1 \mathrm{~mm}$ wide Esterline seal fails over craters made by particles of about $180 \mathrm{~J}$ kinetic energy. The energies at which the seals first start to fail, $K E_{\text {crit, }}$ are important observations that enable us to determine the likelihood of seal failure in the space environment. ${ }^{10}$ Figure 10 shows the kinetic energy plotted with the resulting average crater diameter, $D_{f}$, for hits into aluminum targets. Note that kinetic energy in Table 2 and in the plot is calculated using the speed of the particle, not the velocity component perpendicular to the target. A power law fit of these data yields the following:

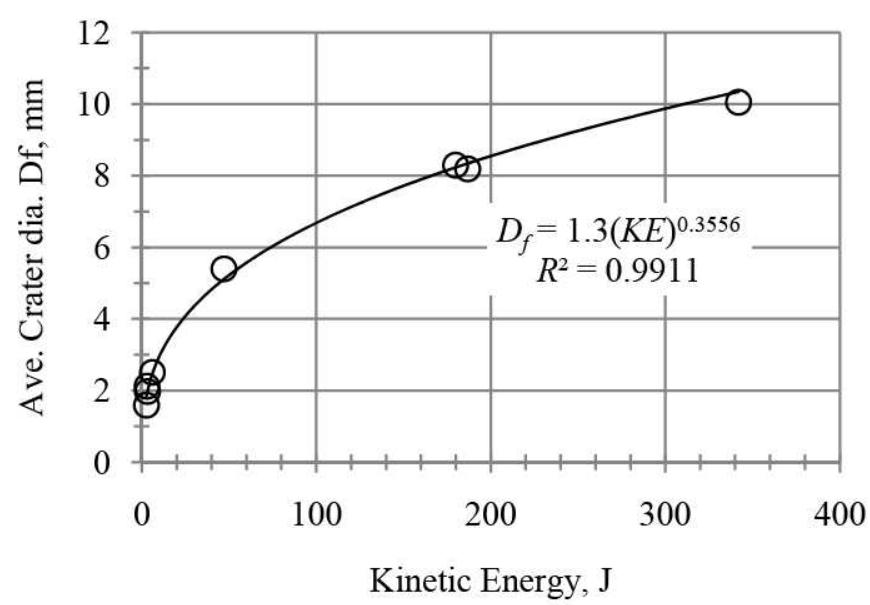

Figure 10. Average Crater Surface Diameter in Aluminum from Impacts of Different Kinetic Energy. Target and projectiles were $6061 \mathrm{~T} 651$ and 2017 T4 aluminum respectively; projectile diameters ranged from 0.4 to $1.6 \mathrm{~mm}$ with velocities from 7.5 to $8.34 \mathrm{~km} / \mathrm{s}$.

$$
D_{f}=1.3(K E)^{0.3556}
$$


where $D_{f}$ is the average surface diameter of the crater in aluminum in units of $\mathrm{mm}$, and $K E$ is kinetic energy of the projectile in units of Joules. Strike 40 was the only impact test done so far with the aluminum target tilted $45^{\circ}$.

1. Effect of Coatings and Incidence Angle

As seen by comparing Strikes $39 \mathrm{~b}$ and 14 , the Ni coating decreased the resulting crater diameter for impacts near $3 \mathrm{~J}$; Table 2 shows that even though the kinetic energy of Strike 39b (Ni coated) was higher than in Strike 14 (asreceived) the resulting crater was larger in the as-received plate. While compensating for kinetic energy (using $\mathrm{KE}^{0.3556}$ from Eq. (1) we would expect the crater diameter in Strike 14 to be about $7 \%$ smaller than the crater produced in Strike 39b; but the crater in Strike 14 was actually about $7 \%$ larger compared to Strike $39 \mathrm{~b}$. This is believed to be due to the electroless nickel coating present on the Strike $39 \mathrm{~b}$ target, which changed the surface properties (e.g., increased surface strength) compared to the as-received surface used in Strike 14. Anodizing appears to similarly change the surface, resulting in smaller craters compared to as-received aluminum; as shown by comparing Strike 14 (as-received) to Strike 13 (anodized). Based on kinetic energy, it is expected that the crater of Strike 13 should be about 30\% larger than in Strike 14, but it was only about $18 \%$ larger. It is believed that this is due to the harder anodized surface compared to as-received 6061 T651 aluminum. Any influences of such nickel coatings or anodizing are expected to decline as the energy of impact increases, as indicated by Strikes 23 (asreceived) and 19 (anodized), which had similar kinetic energies, near $180 \mathrm{~J}$, and crater sizes.

The tempered effects of incidence angle can be seen by comparing Strike $39 \mathrm{~b}$, which came in normal to the target's surface, to Strike 40 , which had an incidence angle of $45^{\circ}$. The crater from Strike $39 \mathrm{~b}$ (normal) was $24 \%$ larger than the crater from Strike $40\left(45^{\circ}\right)$; but the speed based kinetic energy of Strike $39 \mathrm{~b}$ was $24 \%$ larger as well. Since $D_{f}$ is proportional to $K E^{0.3556}$ this $24 \%$ increase in kinetic energy is expected to increase crater size by about $8 \%$, thus the difference in crater size between Strikes $39 \mathrm{~b}$ and 40 cannot be accounted for on the basis of speed based kinetic energy alone. If we consider kinetic energy on the basis of projectile velocity normal to the target surface, the energy of Strike 40 would be lowered to $1.31 \mathrm{~J}$; the use of this kinetic energy over compensates and would result in a crater about $38 \%$ smaller than the Strike $39 \mathrm{~b}$ crater. The surface diameter of craters in aluminum appears to be influenced by incidence angle but to a lesser extent than would be predicted by use of the velocity component normal to the surface.

\section{Crown Height}

Strike 23 provides an example of some of the complexities of seal failure. There is a peak in the crown height near $180 \mathrm{~J}$ (Strike 19) for impacts such as these into aluminum; at this kinetic energy, the crater's crown is most full and intact and causes the leakage failure for this particular Esterline seal. At energies greater than $180 \mathrm{~J}$ the crown height declined; parts of the crown appeared to get blown off and the seal did not fail (Strike 23). As kinetic energy is raised further, the crater diameter increases and causes failure, as seen in Strike 11. In our analysis of the Esterline seal, we assume all impacts equal to or greater than $180 \mathrm{~J}$ cause seal failure. Note also that the Parker seal did not fail when placed over the crater produced in Strike $39 \mathrm{~b}$, even though it did fail over the crater of Strike 14, which was less energetic than Strike 39b. This might be due in part to the nickel coating on the target of Strike $39 \mathrm{~b}$; the target in Strike 14 was as received thus was not nickel coated or anodized.

\section{Impact Location and Leakage}

Figure 11 shows several leakage tests of a $10 \mathrm{~cm}$ diameter Parker Gask-O-Seal (Fig. 2) placed over the crater made in Strike 14 (Table 2). This simulates impacts on the metal flange on ISS or Altair at different locations near where the center-line of the seal would land during docking. Note that leakage was significant only when the crater was at the seal's center-line. Also shown in Fig. 11 is an illustration showing the position of the elastomer inner diameter (ID) relative to the crater helping define "c-c". Figure 12 shows the leakage results for an undamaged Esterline seal placed over the crater resulting from Strike 11 (Table 2). For this case shown in Fig. 12, for the Esterline seal to fail from an impact of this kinetic

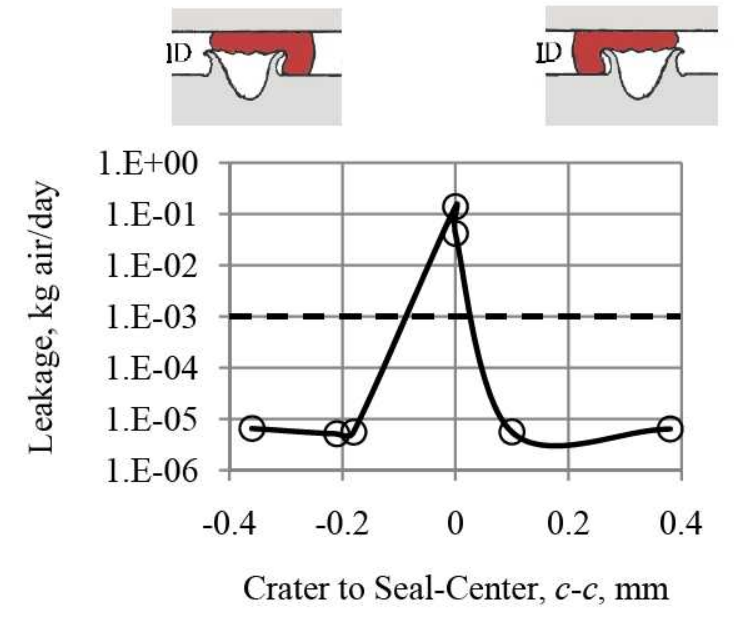

Figure 11. Leakage tests with a Parker Gask-OSeal placed at different locations over Strike 14 crater. Schematic above the graph shows the crater closer to the inner diameter, ID, on the left for negative $c-c$, and the crater closer to the OD on the right, for positive $c$-c. The ID is the high pressure side. Dashed line is the maximum leakage allowed failure criteria of $0.001 \mathrm{~kg}$ air/day. 
energy on the flange, the impact must hit the flange within about $0.8 \mathrm{~mm}$ of where the center-line of the seal will sit during docking. Sets of leakage tests like these were done for all of the impacts done on aluminum targets and were used to make the pass/fail judgments based on leakage noted in Table 2, which enabled estimates of failure criteria for the seals being tested. Table 2 lists the ratio of the average crater diameter, $D_{f}$, and the width of the seal, $w_{\text {bulb }}$, in percent, and shows that the Parker seals fail when the crater in the flange material is greater than $85 \%$ of the width of the seal; or $>90 \%$ for Esterline.

\section{E. Elastomer Seal Targets}

\section{Impact Location and Seal Damage}

Consideration of crater size as a function of kinetic energy is more complicated when considering the elastomer seals compared to the semi-infinite flange materials because the level of damage done to the seal is dependent on where on the seal the projectile strikes. If the particle misses the seal bead, no damage is done. If the particle hits the seal bead near an edge, close to the inner or outer side-wall, the high pressure that develops on impact is relieved due to the hit's close proximity to the side-wall. An example of this is provided by Strikes 6 and $6 \mathrm{~b}$ (Table 3). Strike 6 hit near the side wall, about $1 \mathrm{~mm}$ from the seal's center-line, caused a crater $1.4 \mathrm{~mm}$ wide, and did not cause a failure. Strike $6 \mathrm{~b}$ had the same kinetic energy but hit near the seal's center-line $(c-c=$ $0.167 \mathrm{~mm}$ ), created a crater $3.3 \mathrm{~mm}$ wide, and caused a seal failure. Figure 13 compares images of these two impacts. Figure 14 shows the crater diameter of several hits of approximately the same kinetic energy ( $2.9 \pm$ $0.2 \mathrm{~J}$ ), where on the Parker seal they hit, and how damage decreases at hit locations away from the seal's centerline of $c-c=0$. This facet of how seal damage is dependent on impact location is not integrated into our power law relations presented below. The conservative approach of assuming the maximum level of damage (the damage incurred in impacts near the seal's center-line) was employed when developing crater diameter as a function of projectile kinetic energy relations.

Tables 3 and 4 provide ratios of measured seal crater diameter to bulb width in terms of percentages for both Parker and Esterline compounds. Comparing the percent damage levels and corresponding leakage levels, one can see for crater diameters less than $84 \%$ of the bulb width, the seals exhibited very low leakage.

\section{Effect of Low Temperature and Incidence Angle on} Seal Damage

Due to concern that damage from a hypervelocity impact in space might increase at low temperatures, a small, targeted group of impacts were done at $-78{ }^{\circ} \mathrm{C}$, which is the lowest temperature expected for the LIDS seals during missions. Strikes $8 \mathrm{c}$ and $38 \mathrm{~b}$ in Table 4 provide a good comparison of how Esterline's compound responds to low temperature, since these two impacts were nearly identical except for temperature. As shown by the crater diameters in Table 4, and in Fig. 15, the level of secondary damage and radial cracking was less at the lower temperature. By comparing Strikes 17 and $35 \mathrm{~d}$ we see that damage was similarly less at the lower temperature for the Parker

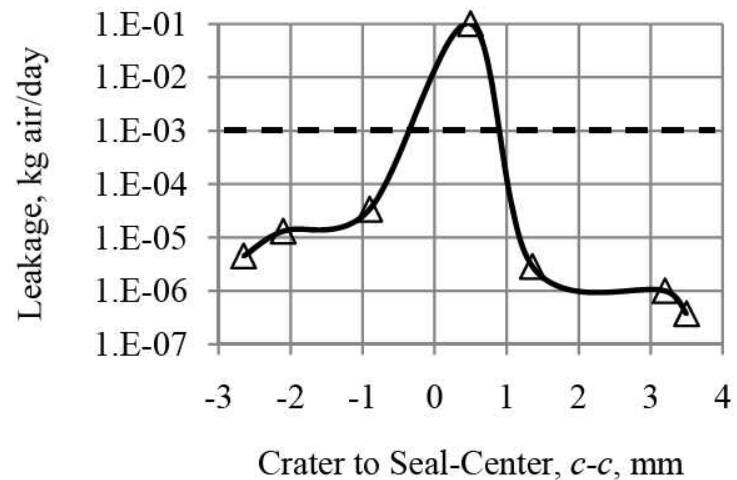

Figure 12. Leakage tests with an Esterline seal place at different locations over the crater resulting from Strike 11. Dashed line is the maximum leakage allowed failure criteria of $0.001 \mathrm{~kg}$ air/day.

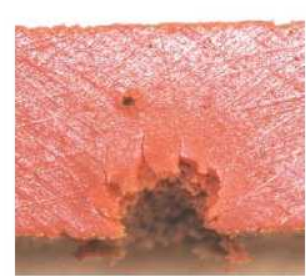

a)

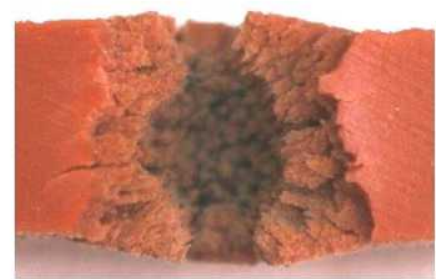

b)
Figure 13. Effect of Strike Location on Seal Damage. Parker $2.5 \mathrm{~mm}$ seal hit near the side wall in a) Strike 6; and hit near the seal's center-line in b) Strike 6 b. Both hits with aluminum projectiles of $10.7 \mathrm{~J}$ kinetic energy.

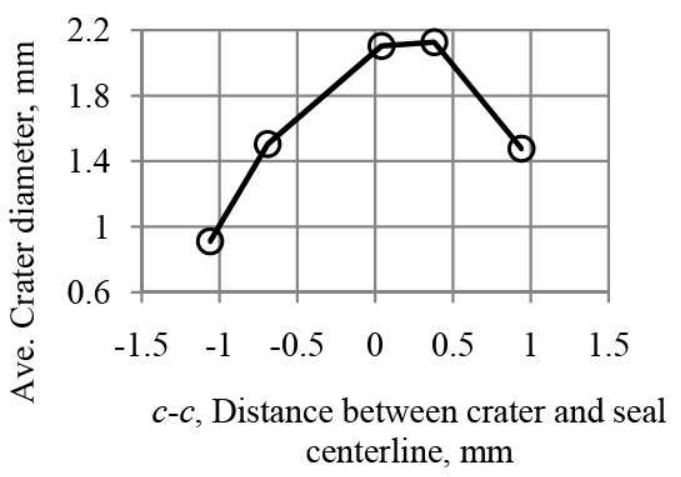

Figure 14. Crater Size vs. Hit Location. Parker Strikes 9, 17, 31, 35c and 35d all with kinetic energy near $2.9 \mathrm{~J}$. 
elastomer (see Table 3 and Fig. 15). However, the vaporized portion of the elastomer, $d_{v}$, was not significantly affected. An estimate of the level of damage at the two temperatures (room temperature and $-78^{\circ} \mathrm{C}$ ) independent of kinetic energy can be made by dividing the crater diameter for a particular test by the kinetic energy raised to the appropriate power provided in Eq. (2) or (3). This was done for room temperature Strikes 8c, 9, and 17 and low temperature Strikes $35 \mathrm{c}, 35 \mathrm{~d}$, and $38 \mathrm{~b}$ which are shown in Fig. 16. Average crater diameters at low temperatures were about $25 \%$ smaller than craters of similar kinetic energy made at room temperature.

Although the number of tests was very limited, projectile incidence angles of $0^{\circ}$ and $45^{\circ}$ away from normal to the target appeared to produce similar levels of damage in the Parker elastomer. Strikes 9 and 17 were at $0^{\circ}$ (normal) and $45^{\circ}$ respectively, had similar kinetic energies based on speed, and resulted in similar levels of damage.

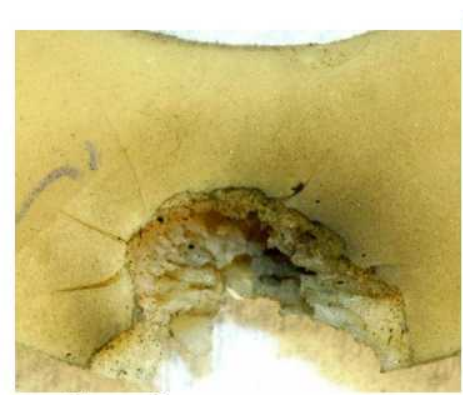

(a) Strike $8 \mathrm{c}, \mathrm{T}=20^{\circ} \mathrm{C}$

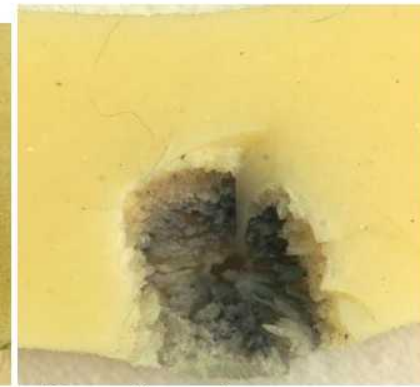

(b) Strike $38 \mathrm{~d}, \mathrm{~T}=-78^{\circ} \mathrm{C}$

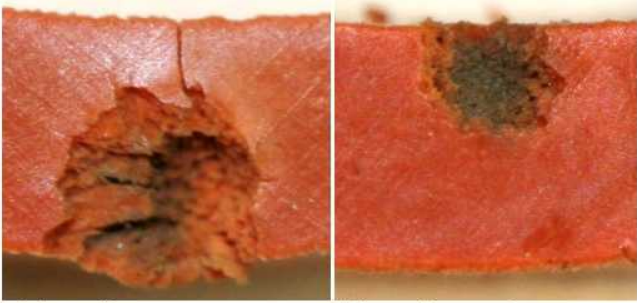

(c) Strike $17, \mathrm{~T}=20^{\circ} \mathrm{C}(\mathrm{d})$ Strike $35 \mathrm{~d}, \mathrm{~T}=-78^{\circ} \mathrm{C}$

Figure 15. Effect of Low Temperature on Hypervelocity Impact Damage in Elastomers. Radial cracking and secondary damage was less at the lower temperature for hits of similar kinetic energy; $d_{v}$ was not significantly affected. (a)-(b) $9.1 \mathrm{~mm}$ wide Esterline seals, (c)-(d) $2.5 \mathrm{~mm}$ wide Parker seals.

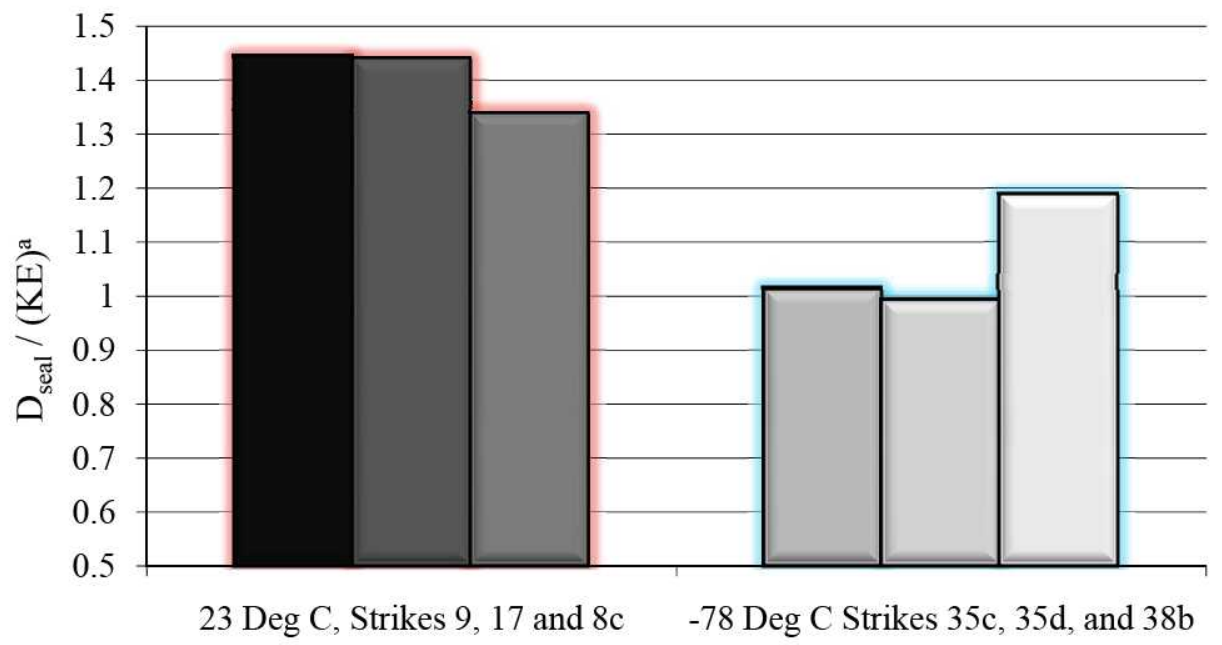

Figure 16. Average Seal Crater Diameter at Different Target Temperatures. $D_{\text {seal }}$ is divided by kinetic energy raised to the "a" power, where $a$ is the exponent from Eq. (2) for Parker, and Eq. (3) for Esterline. 


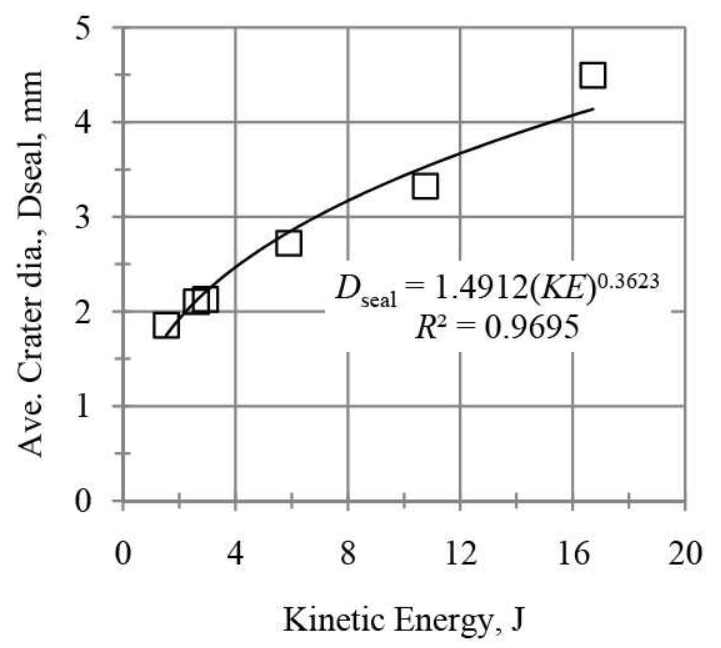

Figure 17. Average Crater Surface Diameter in Parker 0S383-70 from Projectiles of Different Kinetic Energy. Hits more than $25 \%$ of the seal width away from the center-line, and hits at low temperatures omitted. Data included is shown in gray in Table 3.

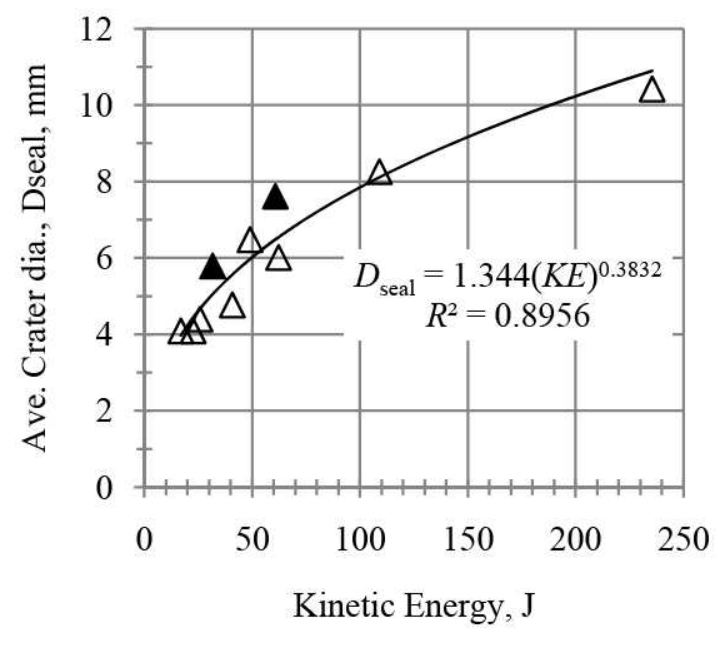

Figure 18. Average Crater Diameter in Esterline ELA-SA-401 from Projectiles of Different Kinetic Energy. Hits more than $25 \%$ of the seal width away from the center-line, and at low temperatures omitted. Data shown in gray in Table 4. Filled triangles indicate Nylon projectiles.

\section{Seal Average Crater Diameter and Kinetic Energy Power Law Relations}

To facilitate seal design sensitivity to various particle kinetic energy hits, equations are needed relating seal damage to kinetic energy. Results from tests at low temperatures and hits near seal side walls were omitted when considering crater size as a function of projectile kinetic energy. Impacts further than $26 \%$ of the seal width from the seal center-line were not included in the following generation of crater diameter versus kinetic energy relations. Table 3 shows the tests included in Fig. 17, shaded gray, and used to determine the power law function for the Parker elastomer:

$$
D_{\text {seal }}=1.491 K E^{0.3623}
$$

The leakage data in Table 3 indicate that the minimum kinetic energy required to cause a seal failure is about $2.6 \mathrm{~J}$ for the $2.5 \mathrm{~mm}$ wide Parker seal. The $K E_{\text {crit }}$ value for Esterline seal failure distilled from Table 4 is $60 \mathrm{~J}$.

The shaded gray data in Table 4 are presented in Fig. 18 which shows the power law function found for the Esterline elastomer:

$$
D_{\text {seal }}=1.344 K E^{0.3832}
$$

Similar power law relations between crater diameter and kinetic energy were presented in Ref. 10, though some of the constants and exponents are slightly different due to current changes in the particle diameters used for the glass projectiles. These exponents can be expected to change slightly as additional data becomes available.

The filled triangles in Fig. 18 are results from impacts using Nylon66 projectiles and show the limits of using kinetic energy in relation to average crater diameter, $D_{\text {seal }}$. Kinetic energy might relate well to aspects of hypervelocity impact damage, such as depth of penetration, however, we are interested in how the damage interacts with the LIDS seal, thus need to solve for damage aspects near the surface of the target because it is these surface aspects, like surface crater diameter, which cause seal failure. Particles of relatively low density yield larger than expected crater diameters when considering kinetic energy only because the volume of the low desity particle is relatively large, thus it has a larger footprint when landing on the target, thereby causing a larger crater at the surface. This is shown in Fig. 19 which compares the craters made in Strike 1, made by an aluminum projectile, to Strike 18, which was made by a Nylon66 projectile. Based on Eq. (3) one would expect the higher kinetic energy of Strike 18 to result in a crater about $8 \%$ larger than the Strike 1 crater. However, the low density Strike18 case 


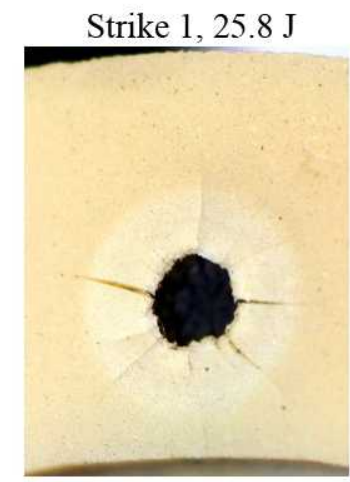

$\rho=2.79 \mathrm{~g} / \mathrm{cm}^{3}$

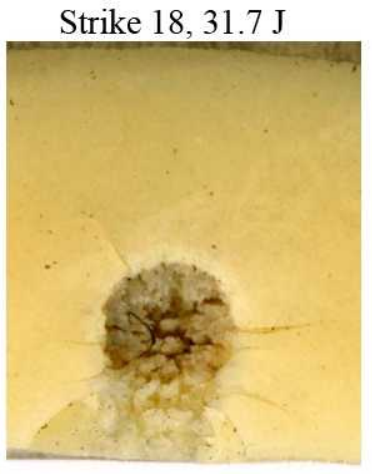

$\rho=1.14 \mathrm{~g} / \mathrm{cm}^{3}$
Strike $10,62.2 \mathrm{~J}$

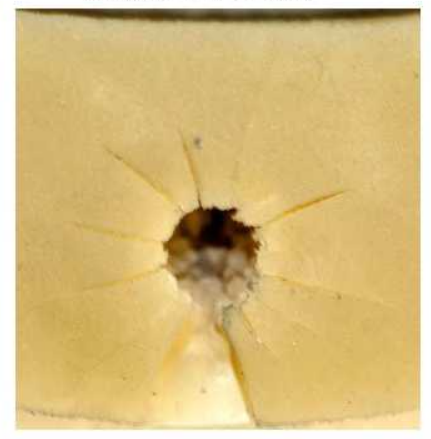

$\rho=2.5 \mathrm{~g} / \mathrm{cm}^{3}$
Strike $16,60.7 \mathrm{~J}$

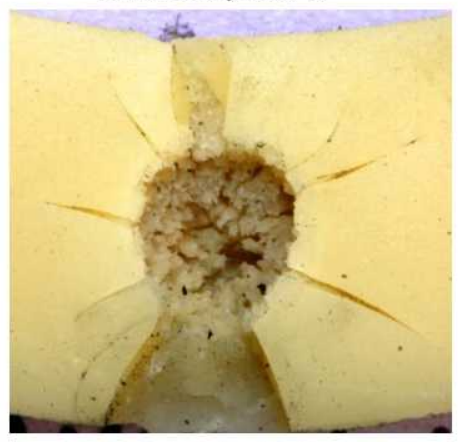

$\rho=1.14 \mathrm{~g} / \mathrm{cm}^{3}$

Figure 19. Craters in $9.1 \mathrm{~mm}$ wide Esterline seals from projectiles of high and low density. Craters from low density projectiles are larger than those made by higher density projectiles of similar kinetic energy.

resulted in a crater about 30\% larger. Figure 19 also shows that the Nylon66 projectile of Strike 16 made a larger crater than the aluminum projectile of Strike 10 even though Strike 16 had slightly lower kinetic energy.

If we consider Eq. (1) for aluminum targets, and substitue $K E=m V^{2} / 2=\pi d^{3} V^{2} \rho_{p} / 12$, we get:

$$
D_{f}=1.3\left(\pi d^{3} V^{2} \rho_{p} / 12\right)^{0.3556}=0.807\left(d^{1.067} V^{0.71} \rho_{p}{ }^{0.3556}\right)
$$

and from Eq. (2) for the Parker elastomer we get:

$$
D_{\text {seal }}=0.9176\left(d^{1.087} V^{0.7246} \rho_{p}^{0.3623}\right)
$$

These powers of $d, V$, and $\rho_{p}$ are frequently seen in the literature and are a direct result of the assumption that kinetic energy controls the level of damage to the target. The units of $D_{f}, d, V$, and $\rho_{p}$ in Eq. (4) are $\mathrm{mm}, \mathrm{m}, \mathrm{m} / \mathrm{s}$, and $\mathrm{kg} / \mathrm{m}^{3}$ respectively. Kinetic energy is an excellent starting point when building relations between projectiles and resulting damage, however, we believe improvements can be made in assessing the surface diameter of craters by emperically tuning the exponents of $d, V$, and $\rho_{p}$. We are currently engaged in aquiring additional data to fine tune these exponents for aluminum targets.

We can also estimate crater diameter using Cour-Palais depth of penetration relations and the approximation that the crater diameter is double the crater's depth: ${ }^{33}$

$$
D_{f \mid C-P}=2 \times 5.24 H^{-0.25} d^{19 / 18}\left(\rho_{p} / \rho_{t}\right)^{0.5}\left(V_{n} / C\right)^{2 / 3}
$$

where $D_{f \mid C-P}$ is in $\mathrm{cm}, H$ is the Brinell hardness of the target, $V_{n}$ is projectile velocity normal to the target, $C$ is the speed of sound in the target, and projectile diameter $d$ is in units of cm. A direct comparison of Eq. (4) and the Cour-Palais depth of penetration relation is illustrated graphically in Fig. 20 for a 6061 T6 aluminum target, and $0.1 \mathrm{~cm} 2017 \mathrm{~T} 4$ aluminum projectile. In the velocity range of 7 to $10 \mathrm{~km} / \mathrm{s}$, the difference between the current work and Cour-Palais' relation is about $29 \%$. This difference is due in part to differences in how the crater diameters are defined. ${ }^{23,34}$ About half of the difference between the Cour-Palais relation and Eq. (4) is due to differences in how the crater diameters are defined. Equation (4) yields the average between the crater's $d_{f i}$ and $d_{f o}$, while the CourPalais relation yields a diameter more characteristic of the crater's inner diameter. ${ }^{23,33,34}$

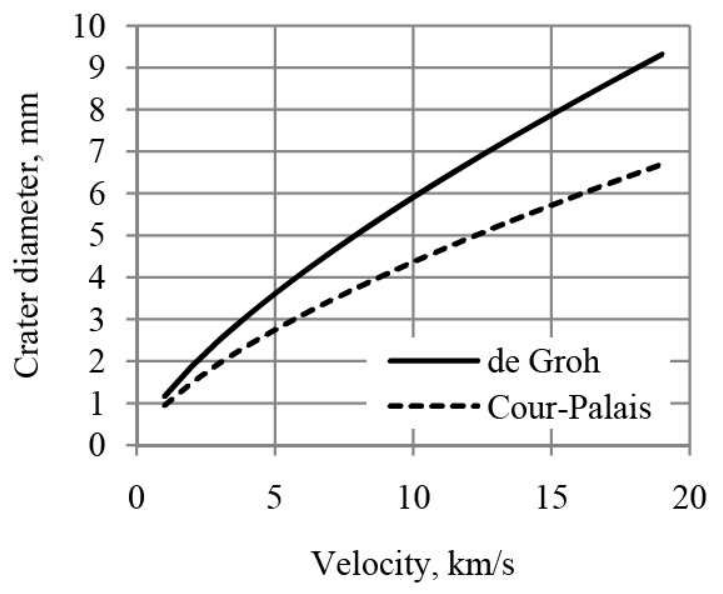

Figure 20. Comparison of the Cour-Palais and de Groh's Eq. (4). Comparison employs 6061 T6 target, and 2017 T4 $0.1 \mathrm{~cm}$ diameter aluminum projectile. 


\section{Summary and Conclusions}

NASA is developing a new Low Impact Docking System (LIDS) to dock future vehicles within the Constellation program. During select portions of the Crew Exploration Vehicle's mission, the LIDS system will be exposed to space environments including threats of impact from Micrometeoroid and Orbital Debris (MMOD) particles. Even though most of these particles are very small (generally less than $1 \mathrm{~mm}$ in diameter), the high speed of these particles can result in significant damage to either the elastomer seal or metal flange which mates with the seal. The objective of this work is to quantify MMOD damage to silicone rubber seals and the metal surfaces these seals mate to, and determine how this damage affects seal performance. Impacts from the MMOD environment were simulated using ground based hypervelocity impacts. This paper presents our results of ground based hypervelocity impacts on silicone rubber seals and aluminum sheet plates along with leakage testing of damaged seals and plates. This study examines damage effects as a function of several key variables including: particle density $(1.14,2.5,2.79$, and 7.7 $\left.\mathrm{g} / \mathrm{cm}^{3}\right)$, particle speed $(5.6 \mathrm{~km} / \mathrm{s}$ and $8 \mathrm{~km} / \mathrm{s})$, incident angle $\left(0^{\circ}, 45^{\circ}, 60^{\circ}\right.$ from normal to the plane of the target), elastomer target material (Parker S0383-70, Esterline ELA-SA-401), aluminum flange treatment (bare, elastomer laminated, anodized, electroless nickel coated). Several measures of the damage were made including the physical damage to either the elastomer material or the simulated flange. Leakage measurements were also performed to determine the threshold level of damage in either the elastomer or the metal flange above which the seal system would exceed the target leakage limit. Findings from this effort are supporting other efforts by DeGroh ${ }^{10}$ to develop an analytical methodology to predict MMOD damage for various mission scenarios and to aid seal design efforts.

The following observations were made:

- Elastomer materials were able to seal surprisingly well after damage. Elastomers were able to seal with crater width less than $84 \%$ of their bulb width. Undamaged elastomer rings were also effective sealing against damaged flange materials. Elastomers were able to seal against aluminum flange craters whose diameters were $80 \%$ to $90 \%$ of the of the seal bulb width.

- There was a strong relation between seal bulb hit location and damage. Particles hitting near the bulb centerline caused greater damage than those hitting near the bulb edge.

- Power law equations were developed relating damage to either the flange or elastomer materials to particle kinetic energy. Though these relations provide reasonable correlation of the data, we observed that the lessdense (e.g., nylon) particles tended to cause greater damage to the elastomer materials per unit kinetic energy than the denser metal and glass particles.

- Elastomers exhibited less secondary damage and less cracking when cold $\left(-78{ }^{\circ} \mathrm{C}\right)$ but exhibited approximately the same level of $d_{v}$ damage in the vaporized core of the crater when compared to specimens impacted at room temperature.

\section{Future Work}

This report describes the results of early phases of the MMOD investigations. Other areas requiring additional work include the following. Additional study is warranted on the effects of lower-density particles on elastomer damage. Additional testing will determine if the power law relations require additional fine-tuning to predict elastomer damage. Work is required to examine effects of high temperature on resulting seal damage, and to assess if molded seal cross-sections behave any differently than rings tested herein.

\section{Acknowledgments}

The authors sincerely thank Donald Henderson and Karen Rodriguez: Don and Karen's great team at White Sands Test Facility did all of the hypervelocity impacts used in this work. We acknowledge the collaboration and contributions of Richard Rauser and Donald Roth for helpful CT work.

\section{References}

${ }^{1}$ Hastings, D., and Garrett, H., Spacecraft-Environment Interactions, Cambridge Univ. Press, New York, 1996, pp. 82-95.

${ }^{2}$ Eckart, P., et al., The Lunar Base Handbook, McGraw-Hill, 1999, pp. 148, 538.

${ }^{3}$ Cour-Palais, B.G. "Meteoroid Environmental Model-1969 (Near Earth to Lunar Surface), Technical Report NASA SP8013, NASA, 1969.

${ }^{4}$ NASA, "Constellation Program Design Specifications for Natural Environments," CxP 70023 Revision A, 2008 , pp. 73.

5 "An Unprecedented Space Collision" Gina Sunseri and Luis Martinez, ABC News, Feb. 12, 2009, http://abcnews.go.com/Technology/Space/story?id=6859247\&page $=1$

${ }^{6}$ "China Confirms Satellite-killing test” Associated Press, msnbc Jan. 23, 2007, http://www.msnbc.msn.com/id/16757285/ 
${ }^{7}$ Lewis, J. L., Carroll; M. B., Morales; R. H., Le; T. D., National Aeronautics and Space Administration, Washington, DC, "Androgynous, reconfigurable closed loop feedback controlled low impact docking system with load sensing electromagnet capture system," U.S. Patent No. 6354540, (2002).

${ }^{8}$ de Groh, K.K., Banks, B.A., and Smith, D.C., "Environmental Durability Issues for Solar Power Systems in Low Earth Orbit," NASA-TM-106775, 1995.

${ }^{9}$ Daniels, C. C., de Groh III, H. C., Dunlap Jr., et. al., "Characteristics of Elastomer Seals Exposed to Space Environments," $43^{\text {rd }}$ AIAA/ASME/SAE/ASEE Joint Propulsion Conf., AIAA-2007-5741, p. 1-16.

${ }^{10}$ de Groh III, H. C., Gallo, C.A., and Nahra, N.K., "Meteoroid and Orbital Debris Threats to NASA's Docking Seals: Initial Assessment and Methodology," AIAA-2009-3524, AIAA paper accepted for publication with the proceedings of the $1^{\text {st }}$ AIAA Atmospheric and Space Environments Conference, San Antonio TX, June 2009.

${ }^{11}$ Coppinger, R., "Congress to Direct NASA to Agree to Common Docking System?" Flightglobal/Blogs, May 20, 2008, http://www.flightglobal.com/blogs/hyperbola/2008/05/congress-to-direct-common-dock.html

${ }^{12}$ Finkbeiner, J. R., Dunlap Jr., P. H., Steinetz, B. M., Daniels, C. C., "Review of Seal Designs on Apollo Spacecraft," J. of Spacecraft and Rockets, Vol. 45, No. 5, Sept-Oct, 2008; also available as NASA/TM-2006-214372 and AIAA-2006-5259.

${ }^{13}$ Williamsen, J. "Review of Space Shuttle Meteoroid/Orbital Debris Critical Risk Assessment Practices," $45^{\text {th }}$ AIAA/ASME/ASCE/AHS/ASC Structures, Structural Dynamics\& Materials Conference, AIAA-2004-1876.

${ }^{14}$ Coombs, C. R. et al., "Environment Modeling in Near-Earth Space: Preliminary LDEF Results," LPSC XXIII, Lunar and Planetary Inst., 1992, pp. 247-248.

${ }^{15}$ Kessler, D. J., Reynolds, R. C., and Anz-Meador, P. D., "Orbital Debris Environment for Spacecraft Designed to Operate in Low Earth Orbit," NASA TM-1000471, 1988.

${ }^{16}$ Cour-Palais, B. G., "Hypervelocity impact in metals, glass, and composites," Int. J. Impact Engng. Vol. 5, 1987, pp. 221-237.

${ }^{17}$ Christiansen, E. L., "Shield Sizing Equations," Technical Memorandum to Distribution, SN3-90-131, Oct. 1990.

${ }^{18}$ Evens, S., et al., "Bounding the risk of crew loss following orbital debris penetration of the International Space Station at assemble stages 1J and 1E," Advances in Space Res., Vol. 34, 2003, pp. 1104-1108.

${ }^{19}$ Lambert, M., "Hypervelocity impacts and damage laws," Adv. Space Res., Vol. 19, No. 2, 1997, pp. 369-378.

${ }^{20}$ Herrmann, W., Wilbeck, J. S., "Review of hypervelocity penetration theories," Int. J. Impact Engng., Vol. 5, 1987, pp. 307-322.

${ }^{21}$ Shanbing, Y., Gengchen, S., Qingming, T., "Experimental laws of cratering for hypervelocity impacts of spherical projectiles into thick target," Int. J. Impact Engng. Vol. 15, No. 1, 1994, pp. 67-77

${ }^{22}$ Watts, A. J., and Atkinson, D., "Dimensional scaling for impact cratering and perforation,” Int. J. Impact Engng. Vol. 17, 1995, pp. 925-935.

${ }^{23}$ Horz, F., et al. "Penetration experiments in aluminum 1100 targets using soda-lime glass projectiles," NASA TM-104813, June 1995.

${ }^{24}$ Christiansen, E. L. "Design and Performance Equations for Advanced Meteoroid and Debris Shields," Int. J. Impact Engng., 14, 1993, pp. 145-156.

${ }^{25}$ Watts A. J., and Atkinson, D., "Dimensional scaling for impact cratering and perforation," Int. J. Impact Engng. Vol. 17, 1995, pp. 925-935, also appearing in NCR-188259, Johnson Space Center, March 1993.

${ }^{26}$ Quasius, B., Pantermuehl, J., "LIDS Seals Design Temperature," Coordination Memo, Jan. 28. 2009.

${ }^{27}$ Anderson, J. C., Henderson, D. J., and Rodriguez, K. M., “.17-caliber Light Gas Gun Velocity Measurement Uncertainty Analysis,"WSTF-IR-1086-001-07, 2007.

${ }^{28}$ de Groh III, H. C., et al., "Adhesion of Silicone Elastomer Seals for NASA's Crew Exploration Vehicle," NASA/TM2008-215433, 2008.

${ }^{29}$ Miller, S. W., unpublished work “Orion Project NASA LIDS Thermal Analysis," Nov. 9, 2007.

${ }^{30}$ Natural Environments Branch, "Constellation Program Design Specification for Natural Environments" CxP 00102, Draft 4R, Dec. 19, 2005, EV13 Spacecraft and Vehicle Systems Dept., Marshall Space Flight Center, pp. 50-53.

${ }^{31}$ Natural Environments Branch, "Constellation Program Design Specification for Natural Environments" CxP 70023, Revision A, Feb. 6, 2008, EV13 Spacecraft and Vehicle Systems Dept., Marshall Space Flight Center, pp. 73-76.

${ }^{32}$ de Groh III, H. C., Daniels, C., Dunlap, P., and Steinetz, B., "Assessing MMOD Impacts on Seal Performance," NASA/CP-2008-215263/Vol2, pp. 143-165.

${ }^{33}$ Christiansen, E., "Meteoroid/Debris Shielding," NASA/TP-2003-210788, 2003, p. 30.

${ }^{34}$ Denardo, P., Summers, J. L., and Nysmith, C. R., "Projectile Size Effects on Hypervelocity Impact Craters in Aluminum," NASA TN D-4067, 1967, p. 4. 